\title{
Cooperation in a Peer Production Economy Experimental Evidence from Wikipedia*
}

\author{
Yann Algan ${ }^{\dagger} \quad$ Yochai Benkler $^{\ddagger} \quad$ Mayo Fuster Morell\$ $\quad$ Jérôme Hergueux ${ }^{\mathbb{I I}}$
}

July 2013

\begin{abstract}
The impressive success of peer production - a large-scale collaborative model of production primarily based on voluntary contributions - is difficult to explain through the assumptions of standard economic theory. The aim of this paper is to study the prosocial foundations of cooperation in this new peer production economy. We provide the first field test of existing economic theories of prosocial motives for contributing to real-world public goods. We use an online experiment coupled with observational data to elicit social preferences within a diverse sample of 850 Wikipedia contributors, and seek to use to those measures to predict subjects' field contributions to the Wikipedia project. We find that subjects' field contributions to Wikipedia are strongly related to their level of reciprocity in a conditional Public Goods game and in a Trust game and to their revealed preference for social image within the Wikipedia community, but not to their level of altruism either in a standard or in a directed Dictator game. Our results have important theoretical and practical implications, as we show that reciprocity and social image are both strong motives for sustaining cooperation in peer production environments, while altruism is not.
\end{abstract}

JEL classification: H41, C93, D01, Z13

Keywords: Field Experiment, Public Goods, Social Preferences, Peer Production, Internet

\footnotetext{
* We gratefully acknowledge financial support from the European Research Council (ERC Starting Grant) and logistical support from the Sciences Po médialab and the Wikimedia Foundation. We are grateful to Anne l'Hôte and Romain Guillebert for outsdanding research assistance. We are greatly indebted to Dario Taraborelli for his instrumental help in moving this project forward, Benjamin Mako Hill and Aaron Shaw for generously sharing some of their data on and Timo Tijhof for coding the recruitment banner in coordination with us. This paper has benefited from invaluable conversations with Philippe Aghion, Nava Ashraf, Rachel Croson, Guillaume Fréchette, Stuart Geiger, Ed Glaeser, David Laibson, Sendhil Mullainathan, Nathan Nunn, Al Roth, Klaus Schmidt, Andrei Shleifer and Gabriel Smagghue. We thank the Berkman Cooperation group and numerous seminar participants at Harvard, Strasbourg and the NBER for helpful comments. Our last thank goes to the Wikipedia community and, in particular, to the 850 Wikipedia contributors who took part in this study.

† Sciences Po, Department of Economics and CEPR. e-mail: yann.algan@sciences-po.fr

‡Harvard Law School and Berkman Center for Internet \& Society at Harvard University. e-mail: ybenkler@law.harvard.edu

$\S$ Autonomous University of Barcelona, Institute of Government and Public Policies. Postdoctoral fellow, Berkman Center for Internet \& Society at Harvard University. e-mail: mayo.fuster@eui.eu

II University of Strasbourg, Institute of Political Studies and Sciences Po, Department of Economics. Research fellow, Berkman Center for Internet \& Society at Harvard University. e-mail: jhergueux@cyber.law.harvard.edu
} 
"The problem with Wikipedia is that it only works in practice. In theory, it can never work."

Kizor, Wikipedia administrator. ${ }^{1}$

\section{Introduction}

Peer production is characterized by the development of large-scale, collaborative and primarily voluntary models of production in some of the most innovative and competitive sectors of information and technology (Benkler 2002, 2006). One flagship of this "New Economy" is the impressive growth of Internet-based voluntary cooperation for the provision of public goods. Over the past 15 years, online communities of volunteers have proven successful at developing and freely releasing highly valued pieces of computer software and information goods which increasingly compete with their firm-based counterparts. ${ }^{2}$ Accordingly, some authors have argued that online peer production is emerging as a novel and sustainable production model (see, e.g., Benkler (2013) for a review). Its distinctive feature would be that it primarily relies on intrinsic motives to incentivize work, as individuals voluntarily selfassign tasks in the absence of price signals and hierarchical authority. Focusing on the seminal case of open-source software, however, Lerner \& Tirole (2002) point out that a sizeable fraction of developers derive some immediate or future monetary benefits from their seemingly "free" contributions, so that much of the dynamics of these projects could in fact be explained through the lens of the standard assumptions of economic theory.

This paper speaks to this debate by studying the prosocial foundations of cooperation in Wikipedia, a peer production economy that has been vastly overlooked in the economics literature so far. ${ }^{3}$ We elicit the social preferences of Wikipedia contributors with an online experiment coupled with observational data, and seek to relate those preferences to subjects' field contributions to the Wikipedia project. As opposed to open-source software, this highly successful peer-production community offers a particularly clean study site, as it is difficult to derive monetary rewards from one's contributions to the project. Besides, it is possible to reliably extract from the Wikipedia website the complete record of editors' contributions to this real-world public good. This allows us to separate out extrinsic from intrinsic motivations to contribute, and study purely the prosocial motivations aspect of peer production, relying on experimental and observational data rather than self-reporting.

Since its inception in 2001, Wikipedia has grown to host over 25 million freely usable articles in 285 languages. Its revealed informational value seems to be enormous to society, as it receives over 80 million unique visitors per month in the United States alone, ${ }^{4}$ and that $60 \%$ of European doctors declare using it for professional purposes. ${ }^{5}$ Every potential Wikipedia contributor, however, faces a simple

\footnotetext{
1 See http://www.nytimes.com/2007/04/23/technology/23link.html?ei=5124\&en=435e5b69b6b3ceac\&ex=13\&_r=0, accessed February 2013.

2 To name a few telling examples, the open-source web browser Mozilla Firefox is currently used by $25 \%$ of all Internet users, the open-source web server Apache serves $63 \%$ of all Internet websites, Wikipedia.org is the $5^{\text {th }}$ most visited website on the Internet and the user-generated game Counter-Strike is one of the most popular and long-lasting video games of a 25 billion dollars industry in the U.S. alone.

${ }^{3}$ One notable exception for our purpose is Zhang \& Zhu (2011).

4 See

http://www.comscore.com/Insights/Press_Releases/2012/9/comScore_Media_Metrix_Ranks_Top_50_US_Web_Properties_for_A ugust_201, accessed February 2013.

${ }^{5}$ See

http://www.pmlive.com/find_an_article/allarticles/categories/General/2011/june_2011/features/dr_wikipedia_will_see_you_no w..._280528
} 
public goods dilemma: while it takes time and effort to contribute valuable content to the encyclopedia, the content contributed by others is immediately available for anyone to see and use at no cost. According to the standard rational actor model, this should lead to no contributions being made in the first place.

Individuals' intrinsic motivations for contributing to a public good can be manifold. In this paper, we focus on the three types of social motives that economic theory has put forward to rationalize people's often observed willingness to sustain cooperation in real-world public goods like environments: (i) altruistic motives, either in the form of "pure altruism" or "warm-glow" (Andreoni 1989; Andreoni 1990; Anderson et al. 1998) (ii) reciprocity motives (Rabin 1993; Dufwenberg \& Kirchsteiger 2004; Falk \& Fischbacher 2006) and (iii) social image motives (Holländer 1990; Bénabou \& Tirole 2006; Andreoni \& Bernheim 2009; Ellingsen \& Johannesson 2008, 2011).

This paper is the first to test for the relative role of each class of social motive for incentivizing sustained contributions to real-world public goods. ${ }^{6}$ Because Wikipedia in itself works as a repeated public goods experiment, we think of it as an ideally suited field for testing the external validity of those theories. On the methodology side, this paper illustrates the potential usefulness of coupling experimental methods with computational social science techniques in order to relieve the tension between internal and external validity in economic experiments. Indeed, while it is possible to leverage large samples and achieve high internal validity with online experiments (Hergueux \& Jacquemet 2013) the Internet also provides a wealth of externally valid observational data on individuals' field behavior (Lazer et al. 2009).

Based on a diverse sample of 850 Wikipedia contributors, we find that measures of reciprocity and social image motives - but not altruism - significantly predict the trajectory of Wikipedia users from a non-contributor to a substantially engaged contributor. Our field experiment thus shows that reciprocity and social image are both strong motives for sustaining cooperation in peer-production environments, while altruism is not. In this process, reciprocity and social image appear as substitutable motivational drivers rather than complementary ones. Because social image motives are difficult to measure experimentally, we exploit the observational data that is available from the Wikipedia website to construct measures of revealed preference for social image within the Wikipedia community. Controlling for a vector of demographic variables, our estimates indicate that moving from no reciprocity to full reciprocity in a conditional Public Goods game and in a Trust game is associated with a $122 \%$ and a $211 \%$ increase in the number of Wikipedia contributions, respectively, while revealing a preference for social image is associated with a fivefold increase in the number of contributions made to the project.

Interestingly, however, our measures of taste for reciprocity do not predict anymore the number of contributions made to the project within the sub-group of super contributors to Wikipedia - who typically exhibit more than 2,000 and up to several hundreds of thousands of Wikipedia contributions while a taste for social image continues to do so, although by a significantly smaller order of magnitude.

\footnotetext{
${ }^{6}$ An extensive literature has investigated the role of those three classes of social motives in people's (lack of) willingness to sustain cooperation in repeated public goods games in the lab, with unequal success. There is some evidence supporting the altruistic motive, although its effect appears to be inconsistent and not quantitatively large (Andreoni 1995; Palfrey \& Prisbrey 1997; Goeree et al. 2002; Andreoni \& Miller 2002; Vesterlund et al. 2009). By contrast, lab experiments have provided strong evidence in support of the reciprocity motive (Burlando \& Guala 2005; Gächter \& Thöni 2005; Page et al. 2005; Cinyabuguma et al. 2005; Charness \& Yang 2007; Gunnthorsdottir et al. 2007; de Oliveira et al. 2009b; Fischbacher \& Gächter 2010). The social image motive is also supported by rather strong experimental evidence (Andreoni \& Petrie 2004; Rege \& Telle 2004; Ariely et al. 2009) and its role has recently been confirmed in careful field experiments (Andreoni et al. 2011; DellaVigna et al. 2012).
} 
Within this highly engaged group, revealing a taste for social image is associated with a 30 to $33 \%$ increase in the number of contributions made to the project.

Finally, we study the contribution patterns of Wikipedia administrators, a particular class of highly engaged Wikipedia contributors who opted-in a very competitive peer-review process at the end of which they were granted with special oversight rights over the encyclopedia in order to perform an important policing role. Within this third group, we find that those who participate relatively more generally exhibit a higher taste for social image, but also a lower taste for reciprocity (and, incidentally, trust, as measured by the Trust game). Again, experimental measures of altruism do not seem to predict contributions patterns within this or any other group.

This paper is related to a burgeoning stream of the literature that has begun to explore the predictive power of experimental measures of social motives on field outcomes. In his seminal work, Karlan (2005) uses the Trust game to obtain individual measures of reciprocity and shows that those can be used to predict loan repayment among participants in a microcredit program. Laury and Taylor (2008) and De Oliveira et al. (2009a) relate the propensity of their subjects to cooperate in a Public Goods game in the lab to their propensity to contribute to a charitable cause in the field. One prominent limitation of those studies, however, is that they both obtain information about "field" behavior in the lab itself, either through highly contextualized experiments or self-reports. In this case, one might worry about possible spurious correlations caused by demand effects and/or subjects' willingness to avoid cognitive dissonance. Benz and Meier (2008) address part of the above concern by collecting field data about their subjects' behavior in a charitable giving situation prior to conducting a charitable giving experiment in the classroom, but the experiments on which they rely to elicit preferences remain highly contextualized. Barr and Serneels (2009) conduct a Trust game among Ghanaian workers and establish a relationship between individual measures of reciprocity and the observed aggregate labor productivity of the firm in which they work. Similarly, Carpenter and Seki (2011) conduct a repeated Public Goods game among Japanese fishermen and show that fishing crews that exhibit higher levels of reciprocity are more productive. Perhaps most similar to the present study, Carpenter and Myers (2010) rely on an experimental measure of altruism (from a standard Dictator game) and an observational measure of social image concerns within a population of volunteer firefighters and non-volunteer community members to show that both preferences predict the decision to join the volunteer fire service. Finally, Fehr and Leibbrandt (2011) and Leibbrandt (2012) conduct a Public Goods game among Brazilian shrimp catchers and sellers, respectively, and show that more prosocial shrimp catchers are less likely to engage in overextraction, while more prosocial shrimp sellers achieve higher prices for the same goods. While both studies convincingly establish that levels of cooperation in a standard Public Goods experiment can predict field cooperation and economic outcomes, they are not designed, however, to answer the question of which specific preferences account for those general cooperative dispositions.

The present study distinguishes itself from the above literature by eliciting and examining the relative predictive power of all three classes of prosocial motives in a comprehensive fashion. It is also the first to concurrently (i) follow the experimental economics standard of relying on highly decontextualized experiments to elicit individual preferences (ii) link those preferences to individual outcomes that were independently collected from the field and (iii) examine a real-world public goods like environment in which extrinsic motives play no role in shaping individual behavior.

The rest of the paper proceeds as follows. Section 2 provides some knowledge background on the Wikipedia project and its community of contributors. Section 3 documents the design and implementation of the study. We report the empirical results in section 4 . Section 5 provides a discussion of our findings and concludes. 


\section{Background on Wikipedia}

Wikipedia is a free online encyclopedia that is collaboratively edited by volunteers over the Internet. The Wikipedia project originates in Jimmy Wales and Larry Sanger's attempt at creating a traditional, extensively peer-reviewed online encyclopedia called "Nupedia" in March 2000. The goal of Nupedia was to get scholars and experts to volunteer their work and expertise to the project, with the goal of creating a free equivalent of the existing for-profit encyclopedias. Confronted with the difficulty of taking the project off the ground - Nupedia only got 21 articles finalized in its first year - Wales and Sanger eventually released Nupedia's content over the Internet in January 2001 as an open side project, called "Wikipedia", whose original purpose was to feed Nupedia with additional draft articles. Wikipedia quickly overtook Nupedia and became a multiple language popular project of its own, with over 20,000 encyclopedia articles created in its first year and an exponential growth of its content and contributor base since then.

Since 2003, Wikipedia has been operated by the Wikimedia Foundation, a small San Francisco-based non-profit organization, whose role is to pay the bandwidth bills, buy the servers and provide legal defense for the project. The Wikimedia Foundation mostly leverages the capital that it needs to perform this function through donations. It is important to note that while the Foundation is interested in developing technical and social solutions that could support volunteers' editing work, it has never been directly involved in developing Wikipedia's content or managing its community of contributors. This is a matter of principle, and the relationships between the Wikimedia Foundation and the body of engaged Wikipedia contributors have sometimes been notably tense, as some would repeatedly suspect the Foundation of covertly trying to influence the evolution of the project and direct its development.

On the technological side, Wikipedia is based on the wiki system, which allows the reader of any Wikipedia page to modify it easily and rapidly by clicking on an "edit" button. As a result, there exist no limitations à priori as to whom can contribute content to the encyclopedia. Many regular contributors choose to create a Wikipedia account in the website, notably because it gives them access to very useful editing tools. One prominent example of such tools is the so-called "watchlist", which allows registered users to mark pages of interests and closely follow their evolution through automatic notices whenever a modification is implemented to them by another editor. The wiki system archives each and every version of a given page in a revision history, together with the username of the registered contributor who authored the revision. This feature allows the reader of any page to get a very quick sense of the modifications recently implemented to it and, if necessary, easily revert it to one of its previous state. It is not necessary, however, to create a Wikipedia account in order to contribute content to the encyclopedia, as this can be done "anonymously" in the exact same way. In this case, each modification implemented is registered together with the IP address of the computer from which it was performed.

If they create a Wikipedia account, contributors automatically get a personal user page and a user talk page on the Wikipedia website. Those pages, like virtually every other on Wikipedia, can be edited by anyone. User pages are mostly edited by their owners to post some general information about themselves, their interest in Wikipedia, the articles they helped improve and the like. As collaborations between editors mostly form when they notice that they contribute to the same articles, either through its revision history or the watchlist system (as opposed to randomly scrawling contributors' personal user pages in search for an editor with matching interests), those pages are not crucial to the functioning 
of Wikipedia. Hence, a significant number of contributors choose to leave them blank. User talk pages, by contrast, are mainly edited by one's fellow editors. They play a very critical role on Wikipedia, as they are used as a convenient place for contributors to communicate with one another, request help, ask questions and coordinate work. Taken together, those technical features explain that even if many individuals do contribute to Wikipedia without having registered an account, the contributions made in this fashion are more likely to be one-offs and, in any case, cannot be much collaborative in terms of content.

The number of contributions made to Wikipedia by registered users follows a strong power law distribution. As of 2011, about 200,000 individuals register an account on Wikipedia each month. About $2 \%$ of those individuals make 10 contributions or more within their first month, which certainly represents a non negligible influx of new contributors per month in absolute terms. However, only $10 \%$ of those early contributors still make one contribution or more within the following year. ${ }^{7}$ As a result, the relatively limited body of editors who eventually become engaged and reach the threshold of 100 Wikipedia contributions was still responsible for almost $70 \%$ of all the contributions made in 2007 (Kittur et al. 2007). Even within the group of editors who become engaged with the project, individual contribution patterns are still highly heterogeneous. While the vast majority of engaged editors have a few hundred contributions in total, about 5,000 of them made more than 10,000 contributions and about 200 editors have contribution records ranging from 100,000 to 1,000,000 contributions. Overall, the size of the body of active experienced contributors who reached the threshold of 300 contributions is relatively stable since 2007 , revolving around 20,000 individuals.

One surprising fact about Wikipedia is the ability of its community of engaged contributors to successfully synthesize into coherent and structured articles their often competing or opposed views about the topics at hand in a civil way. In this respect, it is interesting to note that among subjective topics, more controversial ones are on average better treated in Wikipedia, precisely because they attract attention from a larger and more diverse pool of contributors (Greenstein \& Zhu 2012). Reagle (2010) provides a very detailed account of how relationships within the community of engaged editors are generally driven by common behavioral norms that emerged through progressive consensus building as it faced collective action problems. One paradigmatic example of such a norm is the "neutral point of view" policy. It is remarkable that this policy doesn't state that editors should strive to be "neutral" or "objective" while contributing to a given article, but that a "fair" representation of all sides of the dispute should be sought. Conditional on being able to support one's point with reliable secondary sources, this guiding principle has the positive effect of shifting many debates from the question of whether it should be included in the article to the question of how it should be included. Another example is the "assume good faith" principle, which exhorts editors to approach others' contributions as being made in good faith and trying to help the project, unless there is specific evidence of malice. When direct discussion fails to resolve disputes among contributors, this is usually achieved by extending the debate to a larger audience, or seeking the mediation of a third party.

Besides the sheer number of contributions that they make to Wikipedia, the body of engaged contributors is thus key to the project, as they often make contributions across topical boundaries in order to curate the content and turn it into a comprehensive resource, help newcomers learn the behavioral norms and attitudes that will allow them to connect with others and make valuable contributions to the project and informally mediate disputes. In this sense, engaged Wikipedia

\footnotetext{
${ }^{7}$ See http://stats.wikimedia.org/EN/TablesWikipediaEN.htm and http://strategy.wikimedia.org/wiki/Editor_Trends_Study/Results, accessed February 2013.
} 
contributors create the public good value of the encyclopedia, and distinguish its contributor base from a broad collection of individuals trying to push their own personal agendas within the site.

One particular class of engaged contributors, the Wikipedia administrators, are in charge of dealing with disruptive editors when good faith discussion and basic explanations about what the goal of the project is fail. To do so, they are entitled with special oversight rights over the encyclopedia that allows them to enforce the behavioral norms of the community, notably by blocking malicious editors and protecting vandalized pages. To obtain those policing rights, those engaged contributors decided to participate in a very competitive peer-review process that would require them to prove through their contribution history that they can handle heated debates and make difficult decisions.

\section{Design of the study}

In this section, we first describe our strategy for measuring social motives among our subjects. We then describe our experimental procedure before reporting on the practical implementation of the experiment.

\section{1 Measuring social preferences}

We elicit social motives among our subjects using experimental data from five mostly standard decision problems taken from the literature on social preferences (see, e.g., Fehr \& Camerer 2004) coupled with observational evidence. We systematically provide two different measures for each social motive, so that we can check for the consistency of our results. At the beginning of the experiment, subjects are sequentially attributed a role (according to their login order): either participant $\mathrm{A}$ or participant B. The assigned role remains the same during the whole experiment. At the end of the experiment, we ask subjects some standard demographic questions about their age, gender, education and salary level, along with an experimentally validated question on risk aversion taken from Dohmen et al. (2011).

(i) Cooperation. As we are interested in studying the prosocial foundations of cooperation in Wikipedia, we start by eliciting our subjects' propensity to cooperate in a very standard Public Goods dilemma (see figure 1 which pictures the Public Goods game instructions screen). Subjects play in groups of four with an initial endowment of $\$ 10$ per player. Each euro invested in the common project by a member of the group yields a return of 0.4 euro to each group member. ${ }^{8}$ Subjects have to decide on how much of their $\$ 10$ they want to invest in the common project. We take the proportion of the endowment that is unconditionally contributed to the public good as a measure of subjects' propensity to cooperate when confronted with a social dilemma.

[FIGURE 1 ABOUT HERE]

\footnotetext{
${ }^{8}$ Each subject thus faces the following payoff function: $\pi_{i}=10-$ contrib $_{i}+0,4 \sum_{j=1}^{4}$ contrib $_{j}$
} 
Right after the decision screen, we ask subjects about (i) their normative opinions about how much people should contribute to the public good and (ii) their beliefs about how much the other members of their group actually contributed on average. We then go about eliciting each of the three classes of social motives that has been put forward by economic theory to explain people's willingness to sustain cooperation in the field.

(ii) Reciprocity motive. Following Fischbacher et al. (2001), we use a modified version of the above Public Goods game to elicit subjects' reciprocity motive. Implementing the so-called "strategy method", we ask subjects to provide their intended contribution for each possible value (on the scale of integers from 0 to 10) of the average contribution of the three other members (see figure 2 for the corresponding decision screen). Subjects are told that their actual contribution to the common project will be randomly determined to be either their unconditional contribution from the standard Public Goods game or their current conditional contribution decision. We take the average proportion of the endowment that is conditionally contributed in the conditional Public Goods game as a measure of subjects' reciprocity motive.

\section{[FIGURE 2 ABOUT HERE]}

In order to provide an alternative measure for the reciprocity motive, we also conduct a standard Trust game among our subjects. Each participant $\mathrm{A}$ is matched with a participant $\mathrm{B}$, and both players receive a $\$ 10$ initial endowment. Participant A is the trustor and chooses how much of his endowment is transferred to participant $\mathrm{B}$ - the trustee. The trustee receives three times the amount sent by the trustor, and chooses how much is sent back to him. We elicit this decision through the strategy method: for each possible transfer from the trustor (from 1 to 10) the trustee chooses how much will be returned without knowing the trustor's actual choice. We take the average proportion of the amount received that is returned by the trustee in the Trust game as an alternative measure of subjects' reciprocity motive.

(iii) Altruistic motive. The Dictator game is certainly experimental economics' workhorse for studying altruistic motives. We thus use a standard Dictator game to elicit this preference among our subjects. ${ }^{9}$ Each participant $\mathrm{A}$ is matched with a participant $\mathrm{B}$ to play as a dictator. The dictator receives a $\$ 10$ endowment, of which he must decide on how much is transferred to participant B. We take the proportion of the endowment transferred by the dictator as a measure of subjects' altruistic motive.

As we worry that the standard Dictator game may not capture subjects' altruistic motive if they are incentivized to contribute to Wikipedia out of altruism directed towards their fellow contributors, we provide an alternative measure for this motive by conducting a second Dictator game in which we induce some in-group bias. We do this by telling subjects that they are now matched with another subject who "participates in online collaborative projects such as open source, free software or Wikibased authoring projects". We take the proportion of the endowment transferred by the dictator in this directed decision as an alternative measure of subjects' altruistic motive.

(iv) Social image motive. Social image motives are difficult to measure experimentally - even more so in a decontextualized fashion, that is, out of a given social context. As a result, we rely on the observational data available from Wikipedia in order to elicit this preference. Specifically, we collect the

\footnotetext{
${ }^{9}$ Note that the measures of altruism that we get from our Dictator games add-up the theoretically distinct "pure altruism" and "warm glow" motives. In this paper, we thus consider the joint effect of those two sub-components of altruism.
} 
size (in bytes) of the personal user pages of our subjects and use this information to construct a measure of revealed preference for social image within Wikipedia (recall from section 2 that personal user pages do not play an important functional role in Wikipedia and are mainly used to present oneself to the community of contributors). Separating out regular contributors from Wikipedia administrator, we code as "social signaler" those who have a personal Wikipedia user page whose size (in bytes) is higher than the median in their group, and take this variable as a measure of subjects' social image motive.

In order to provide an alternative measure for subjects' social image motive, we exploit Wikipedia's main social rewarding practice: the Barnstars system. A Barnstar is a symbolic award constituted of an image accompanied by a personalized message acknowledging some important contribution made to the project by an editor (see figure 3 for an example). ${ }^{10}$

\section{[FIGURE 3 ABOUT HERE]}

In theory, anyone can give or receive a Barnstar. This practice, however, remains largely limited to the body of engaged Wikipedia contributors who display relatively impressive contribution records. Barnstars are typically posted on a contributor's talk page. They thus appear within the flow of discussions between this contributor and the rest of the community. After some time, a particular discussion thread is likely to be archived and/or become too long for anyone to easily notice that an award had been given. Some Wikipedia contributors choose to circumvent this by manually moving (some of) their Barnstars to their personal user pages (or some particular subsection of their user page generally labeled their "awards page"), so that they would be durably and prominently displayed for any other editor to see. We take such decisions as revealing a contributor's motive for social image. From the subsample of subjects who received Barnstars (about $54 \%$ of our sample, the vast majority of whom are highly engaged contributors), we code as "social signalers" those who decided to display at least one of those awards on their personal user page, and take this variable as an alternative measure of subjects' social image motive.

\section{2 Experimental procedures}

The online implementation of the experiment requires a fully self-contained interface, so that every communication between the subjects and the experimenter has to proceed through the screen. The welcome page of the decision interface provides subjects with general information about the experiment, including the number of sections, expected completion time (about 25 minutes) and how their earnings will be computed. In order to minimize potential demand effects and in-group biases when eliciting subjects' social motives, we were very careful not to present the study as Wikipedia oriented..$^{11}$ Importantly, we made it very clear on the introductory screen that subjects would interact with a diverse pool of Internet users. ${ }^{12}$

\footnotetext{
${ }^{10}$ The Wikipedia "Barnstars" page starts as follows: "It is the custom to reward Wikipedia contributors for hard work and due diligence by awarding them a barnstar. To give the award to someone, just place the image on their talk page (or their awards page), and explain why it was given. If you are sure the barnstar is appropriate, don't be shy!" See http://en.wikipedia.org/wiki/Wikipedia:Barnstars, accessed February 2013.

11 The specific language used on the welcome page was as follows: "Our goal is to better understand the dynamics of interactions and behavior in online social spaces. To do so, we invite internet users with various profiles to fill out an interactive survey. We very much welcome participation from Wikipedia users!" Our strategy for framing the study as non Wikipedia oriented eventually proved more effective than we had anticipated. When we presented this research project to the
} 
Subjects are only informed of their earnings in each game at the very end of the experiment. Final payoffs are equal to the earnings from one randomly selected game plus a $\$ 10$ participation fee (subjects earned on average $\$ 20.50$ from the experiment). Subjects get paid upon completion of the experiment through an automated PayPal transfer. ${ }^{13}$ We only require a valid e-mail address to process the payment. To strengthen the credibility of the payment procedure, we ask subjects to enter the email address that is (or will be) associated with their PayPal account right after the introductory screen of the decision interface. It is important to stress that Wikipedia contributors can be very hostile to monetary rewards. In order to ensure that the experiment is equally incentive compatible for all subjects, we allow them to donate any amount taken from their final earnings to the Wikimedia Foundation and/or the International Committee of the Red Cross - a renowned and general purpose charitable organization, in anticipation of the fact that some subjects might not want to donate to the Wikimedia Foundation - upon completion of the experiment. This possibility was made clear on the welcome screen of the decision interface. It was not possible, however, to commit to donating one's final earnings prior to the study's completion.

All five decisions, followed by the survey, are made successively following a given sequence of screens. The unconditional and conditional Public Goods games are the most cognitively demanding. Accordingly, we always present those two decision problems first to subjects (in this order). As we don't want the Dictator game with induced in-group bias to generate spillover effects on the other decisions, we always maintain both Dictator game decisions in last position. In order to alleviate anchoring effects, we sequentially vary the order in which the standard Dictator game and the directed Dictator game are presented to subject according to their login order. As a result, the standard Trust game was always presented in middle position.

All decisions made by our subjects are anonymous. This is because contrary to the social image motive - which is by definition a public preference - all the preferences that we elicit experimentally are private preferences, meaning that they do not depend on the visibility of one's actions to be at work. ${ }^{14}$ As we want to elicit social motives in isolation from strategic concerns and learning effects, each game is only played once and we match subjects in each game according to a perfect stranger procedure.

One important methodological concern with the online implementation of the experiment is to guarantee a quick and appropriate understanding of the decision problems when no interaction with the experimenter is possible. We strengthen the internal validity of our online experiment with three distinctive features of the interface. First, we include suggestive flash animations illustrating the written experimental instructions at the bottom of each game's instruction screen (see figure 2 for the example of the standard Public Goods game). ${ }^{15}$ Second, the instructions screens are followed by a

Wikimedia Foundation staff, their initial reaction was: "Several people expressed concerns that there was not a clear connection between the contents of the survey and data that would be strategically useful at this time to Wikimedia community members and the Foundation. [...] We hope that you will find another suitable outlet to recruit participants for your study. We're happy to answer questions about this decision, and we hope in the future to be able to support other projects you may be working on that are relevant to Wikimedia."

12 The Wikipedia subjects were matched with a traditional pool of laboratory subjects and with open-source software developers who both previously participated in a similar online experiment.

${ }^{13}$ Such a payment procedure guarantees a fungibility similar to that of cash transfers in lab experiments, as money transferred via PayPal can be readily used for online purchases or easily transferred to one's personal bank account at no cost.

${ }^{14}$ Note that the concept of "social image motive" as it currently stands in the economics literature conflates several motives (e.g. relative social status within a group or relative competence assessment) all of which crucially depend on the visibility of one's actions to be at work. We do not try to distinguish between those in this paper.

${ }^{15}$ The loop of concrete examples displayed in each animation was first randomly determined and then fixed for each game. The same loop is displayed to all subjects without any other numeric information than the subjects' initial endowments. We decided against displaying a purely random sequence of flash animations as it could have introduced uncontrolled and subject 
screen providing some examples of decisions, along with the detailed calculation of the resulting payoffs for each player. These examples are supplemented on the subsequent screen by earnings calculators. On this interactive page, subjects are allowed to test all the hypothetical scenarios they are interested in before making their decisions in the Public Goods and Trust games. In contrast to the illustrative flash animations, the numeric results of each scenario run by a subject in the earnings calculator screens are explicitly displayed. Last, the system provides a quick access to the instructions material at any moment during decision-making. On all screens, including decision-making ones, a "review description" button gives subjects a direct access to the instructions displayed at the beginning of the game. The system also allows participants to navigate at will from one screen to another - until a decision screen has been passed - through the "Previous" and "Next" buttons located at the bottom of each screen (see figure 3 for the example of the conditional Public Goods game decision screen).

\section{3 Implementation of the experiment}

Our dependent variable of interest is the total number of field contributions that a subject has made to Wikipedia over his history with the project. A Wikipedia contribution, or "edit", is defined as the action of (i) going to a Wikipedia page (ii) hitting the "edit" tab (iii) implementing a modification and (iv) saving the modification. We only recruit from Wikipedia registered users (i.e. individuals who created a Wikipedia account) in order to be able to track subjects' full contribution records. ${ }^{16}$

In order to best explain the dynamics of the project, we want to capture the very wide heterogeneity in registered editors' contributions patterns (see section 2 for some background statistics on this topic). To do so, we decide to recruit our subjects from the three following groups:

(i) The cohort of new Wikipedia contributors, defined as all individuals who registered a Wikipedia account within the 30 days prior to the launch of the experiment, irrespective of the number of contributions (if any) that they made. Eligible population $=190,327$ subjects.

(ii) The group of engaged Wikipedia contributors, defined as all contributors who made at least 300 contributions to Wikipedia and are still currently active (i.e. they made at least 20 contributions in the last 180 days). ${ }^{17}$ Eligible population $=18,989$ subjects.

(iii) The group of Wikipedia administrators. Those highly engaged contributors successfully decided to run for a very selective peer-review process, at the end of which they were entitled with special oversight rights over the encyclopedia in order to perform a policing role. They notably can block disruptive users and protect vandalized pages. Eligible population $=1,388$ subjects.

specific noise-through, e.g., anchoring on a particular behavior or sequence of events. Our goal with those animations was to illustrate the basic gist of each decision problem in an accessible way while avoiding to prime specific numerical examples and results in subjects' mind.

${ }_{16}$ One might worry about selection effects here. To be sure, this paper does not try to generate results that could be generalizable beyond the population of registered contributors to Wikipedia. In terms of the potential bias induced on our estimates by this selection criterion, we think that insofar as the mere action of registering a Wikipedia account can, on average, be interpreted as a step towards becoming a contributor to the project, then the coefficients on our prosocial motives variables, if they are significant in the true population model, should be biased downwards (as we select on having gone through that step already).

${ }^{17}$ Note that this definition of an "engaged contributor" corresponds to the community's criteria for being eligible and able to vote in the 2011 elections of the Wikimedia Foundation Board of Trustees. See http://meta.wikimedia.org/wiki/Board_elections/2011/en\#Prerequisites_to_candidacy, accessed February 2013. 
We use the Wikipedia banner system as a convenient recruitment device for our experiment. The banner system is prominently used by the Wikimedia Foundation for its annual fundraising and is thus relatively familiar even to non Wikipedia contributors. It is also used by the community of editors for purposes of extended internal communication (e.g., to advertise events and other community initiatives). As a result, the banner system is certainly the most powerful and trusted way of reaching out to a wide and diverse audience within Wikipedia. In coordination with the Wikimedia Foundation staff, we coded this recruitment banner so that it would be displayed at the top of every Wikipedia page for all logged-in eligible users, until he or she decided either to click on it, or to disable it (see Figure 4, which features the recruitment banner). ${ }^{18}$

\section{[FIGURE 4 ABOUT HERE]}

Upon clicking on the banner, eligible users were uniquely identified by the system (through their Wikipedia user id number, which then allowed us to collect their entire contribution history to Wikipedia) and redirected to the welcome screen of our experimental economics platform. Within each of the three above-defined experimental groups, our system sequentially allocated subjects to the role of participant $A$ or participant $B$ according to their login order. Those allocated to the role of participant A were in turn sequentially allocated to one of the two possible ordering of the standard and directed Dictator games (in order to alleviate possible anchoring effects). We implemented this procedure both to ensure that we get relatively balanced samples and to randomize the allocation of participants in the role of participant A and participant B. The experiment was launched on December $8^{\text {th }} 2011$ and the banner recruited 850 subjects in 8 hours (i.e. about 2 complete answers per minute).

\section{Results}

We organize the presentation of our results in three steps. We start by presenting some descriptive statistics about our subjects pool. We then rely on our experimental data (i) to study the relationship between subjects' propensity to cooperate in a standard Public Goods dilemma and their field contributions to Wikipedia and (ii) to test for the role of altruism and reciprocity as social motives for contributing to the project. We end this section by presenting our observational evidence regarding the role of social image motives.

\section{1 Descriptive statistics}

Table 1 provides some descriptive statistics per experimental group on (i) the number of Wikipedia contributions made by our subjects (ii) our measures of social motives and (iii) our demographic variables. Overall, we recruited 149 subjects from the cohort of new Wikipedia contributors, 566 from the group of engaged Wikipedia contributors and 120 from the group of Wikipedia administrators. Because the data used to calculate the eligibility metrics was missing for some users in the Wikipedia

\footnotetext{
${ }^{18}$ This was the first (and is still the only) time in the history of the Wikimedia movement that the banner system was left to use by a third-party. Its selective display system remains Wikimedia's most sophisticated one to date.
} 
API, 15 Wikipedia contributors were displayed the recruitment banner and participated in the experiment while not being formally eligible to do so. As we are equally able to track the contribution records of those subjects, we also include them in our analysis. ${ }^{19}$

\section{[TABLE 1 ABOUT HERE]}

For each experimental group, figure 5 compares the distribution of the number of Wikipedia contributions for the whole sample of eligible contributors against our sub-sample of participants. Focusing on the groups of engaged Wikipedia contributors and Wikipedia administrators, we can see that the distribution of the number of Wikipedia contributions for our sub-samples of subjects closely mirror those of the reference groups. We do seem to capture contributors with higher contribution records on average, however, as we can see from both distributions being slightly skewed to the right. We reach a similar conclusion when we focus on the cohort of new Wikipedia contributors. Out of 149 subjects, $62 \%$ have never made any contribution to Wikipedia (as opposed to $73 \%$ in the reference group) and 27\% made between 1 and 10 contributions (as opposed to $25 \%$ in the reference group). $11 \%$ of our new contributors, however, are already highly engaged with Wikipedia and made more than 10 - and up to 273 - contributions to Wikipedia (as opposed to $2 \%$ in the reference group). ${ }^{20}$

\section{[FIGURE 6 ABOUT HERE]}

Another way to look at how representative of the overall population of Wikipedia registered editors our sample of subjects might be is to pool them all together and compare their demographic characteristics against those of the 5,073 registered editors who took part in the 2011 Wikimedia editor survey. Designed by the Wikimedia Foundation, this survey was precisely implemented so as to get as representative a picture as possible of the profiles of Wikipedia editors. ${ }^{21}$ Similar to the present study, it was advertized through a Wikipedia banner. It ran for 7 days over the whole population of registered Wikipedia editors. Table 2 compares the commonly available demographic information in both studies. It appears that demographic characteristics between both samples are very similar. Contrary to the popular perception that most Wikipedia contributors are high school students, we find that they are on average much older ( 33 years old with $48 \%$ of the population being above 29 in our study versus 32 years old with $47 \%$ being above 29 in the Wikimedia editor survey) and more educated (63\% have finished college and $28 \%$ have a Master's or a PhD degree in our study versus 61 and $26 \%$ in the Wikimedia editor survey, respectively). Consistent with the common perception, however, we find the population of contributors to be predominantly male $(90 \%$ in our study versus $89 \%$ in the Wikimedia editor survey).

\section{[TABLE 2 ABOUT HERE]}

Taken together, we interpret the above evidence as suggesting that our sample of Wikipedia subjects is representative of the diversity of contribution patterns and demographic profiles found on Wikipedia.

\footnotetext{
${ }^{19}$ All of the results presented in this paper remain unaffected if we leave those 15 subjects out of the analysis.

20 A Kolmogorov-Smirnov test of the equality of distribution functions confirms this conclusion at $p<0.001$ in all three experimental groups.

${ }^{21}$ See http://meta.wikimedia.org/wiki/Editor_Survey_2011, accessed February 2013.
} 


\section{2 Experimental results on altruistic and reciprocity motives}

Our dependent variable - the number of Wikipedia contributions made by each subject - follows a strong power law distribution. As this distribution is characterized by overdispersion (likelihood ratio test: $p<0.001$ ), we use negative binomial instead of Poisson regressions to properly model the structure of our data. ${ }^{22}$ In all of our below analysis, we consider the group of Wikipedia administrators as a conceptually distinct class of contributors. We therefore analyze this group separately from our sample of "regular" Wikipedia contributors.

Table 3 begins by investigating whether subjects' propensity to contribute in a standard Public Goods dilemma predicts the number of contributions that they made to Wikipedia. Column (1) only includes our demographic control variables. The model globally confirms our qualitative observations from the previous section: being one year older is on average associated with a $1.7 \%$ increase in the number of Wikipedia contributions, while moving from a high school education to getting a Master's degree is associated with a $26 \%$ increase. Being a female, however, is associated with a $44 \%$ decrease in the number of contributions made to Wikipedia. The coefficient on the salary level variable is very close to zero and not statistically significant. Finally, the effect of risk aversion seems somewhat counterintuitive: moving from generally being "unwilling to take risks" to being "fully prepared to take risks" is actually associated with a $43 \%$ decrease in the number of Wikipedia contributions.

We introduce our measure of cooperation in column (2). The coefficient on this variable is positive and highly statistically significant: moving from being a free-rider to being a full contributor in our standard Public Goods game is associated with a $49 \%$ increase in the number of Wikipedia contributions, which is about twice the effect associated with moving from a high school to a graduate education. This average effect conceals an interesting underlying heterogeneity within our population of subjects, however. In columns (3) and (4) we divide our sample of regular contributors in two equal parts according to the median of the number of contributions that they made to Wikipedia (i.e. 1905 contributions, which already represents a rather impressive contribution record) and run the exact same regressions as in model (2) for both sub-populations (thereafter denoted as the "below median" and "above median" groups). We can see that while the coefficient on cooperation increases by $45 \%$ and remains highly statistically significant for the below median group, its value is virtually zero in the above median group. This suggests that the relationship uncovered in model (2) is in fact entirely driven by the sub-population of new to engaged Wikipedia contributors who are not "super contributors". Accordingly, it is interesting to note that while the effect of our demographic variables remains qualitatively the same within the below median group, none of them reliably predict contribution patterns within the group of highest contributors.

Last, column (5) of table 3 presents our result for the group of Wikipedia administrators. Although the coefficient is only significant at the $10 \%$ level, its sign strikes us as somewhat counterintuitive: admin subjects who are relatively more cooperative in the Public Goods game tend, on average, to contribute relatively less to Wikipedia. Within this group, moving from being a free-rider to being a full contributor in the standard Public Goods game is associated with a $54 \%$ decrease in the number of Wikipedia contributions.

\footnotetext{
${ }^{22}$ As a robustness check, we also tried transforming our dependent variable as $\ln (1+$ number of Wikipedia contributions $)$ in order to run OLS regressions, and obtained consistent results (tables available from the authors upon request).
} 


\section{[TABLE 3 ABOUT HERE]}

With those results in mind, we now turn to the theoretical question of interest and start by investigating which private social motive, altruism or reciprocity, better accounts for subject's willingness to sustain cooperation in the field. Panel A of table 4 presents our results for altruism while panel B presents our results for reciprocity. As we have two alternative experimental measures for each social motive, we include them in turn in our models to check for consistency. All the estimations in this table include the same demographic controls as in table 3. Focusing on altruism (panel A), we can see that no statistically significant relationship appears with field contributions. This is true irrespective of whether we consider the whole sample of regular subjects (columns (1) and (2)) or, as in table 3, separate them in two sub-populations according to the median of their number of Wikipedia contributions (columns (3) to (6)).

The picture is completely different when we turn to our measures of reciprocity, however. In columns (1) and (2) of panel B, we see that moving from no reciprocity to full reciprocity in the conditional Public Goods game and in the standard Trust game is associated with a significant $46 \%$ and $56 \%$ increase in the number of Wikipedia contributions, respectively. ${ }^{23}$ Consistent with our findings on cooperation, the effect is both stronger and more statistically significant in the below median group (columns (3) and (4)), while it appears as insignificant in the above median group (columns (5) and (6)). Focusing on the below median group, moving from no reciprocity to full reciprocity is associated with a $122 \%$ and $211 \%$ increase in the number of Wikipedia contributions, depending on the experimental measure of reciprocity that we consider.

Overall, our results so far indicate that subjects' willingness to sustain their contributions to Wikipedia is related to their propensity to contribute in a standard Public Goods dilemma, and that the main private social motive behind such cooperative dispositions is reciprocity as opposed to altruism. ${ }^{24}$ Interestingly, however, those conclusions only apply to the sub-population of new to engaged Wikipedia contributors who are not "super contributors".

We end this section by discussing the last two columns of table 4, which present our results on altruism and reciprocity for the group of Wikipedia administrators. Consistent with what we find within the group of regular Wikipedia contributors, we see no statistically significant relationship between our measures of altruism and the number of field contributions made to Wikipedia. Turning our attention to the reciprocity variables, we find that admin subjects who reveal a relatively lower

\footnotetext{
${ }^{23}$ Here we define "full reciprocity" as the act of exactly matching other players' average contributions in the conditional Public Goods game and of returning the amount that was received in the standard Trust game. In this latter case, "full reciprocity" is thus defined in a strong sense, as the trustee allows the trustor to reap all the efficiencies created through his decision to transfer a fraction of his endowment.

${ }^{24}$ We can take advantage of the fact that all subjects in the experiment participated in the conditional Public Goods game to investigate how the coefficients on the reciprocity measure derived from this game (reported in columns (1), (3), (5) and (7) of table 4 - panel B) behave when we control for either of our measures of altruism in the regressions (see table A.1. in the Appendix). We see that even if the coefficients now fail to reach statistical significance in the whole sample of regular contributors, they change very little and remain statistically significant at the $10 \%$ level in the below median group. This reduction in the statistical significance of the reciprocity coefficients can be explained by the fact that (i) including our measures of altruism in the regressions cuts our samples by half and (ii) our reciprocity measure exhibits a 0.38 and 0.36 correlation coefficient with our measures of general altruism and directed altruism, respectively $(p<0.001$ in both cases). When we focus on the group of Wikipedia administrators, on the other hand, we see that the economic and statistical significance of the reciprocity coefficient presented in column (7) of table 4 - panel B even increases when we control for altruism.

Furthermore, when we include the same reciprocity variable together with our general altruism variable in an OLS regression explaining subjects' contribution decisions in the standard Public Goods game, we obtain that the former is the only one that is significantly related to subjects' willingness to cooperate in the Public Goods dilemma (table available from the authors upon request). We interpret this result as providing some internal support for our above conclusion.
} 
preference for reciprocity in the games tend to contribute relatively more to the project. This pattern is statistically significant at the $5 \%$ level for both reciprocity variables, and is consistent with the result from table 3. Within this group, moving from no reciprocity to full reciprocity is associated with a $88 \%$ and $169 \%$ decrease in the number of Wikipedia contributions, depending on the experimental measure of reciprocity that we consider.

\section{[TABLE 4 ABOUT HERE]}

The finding that the administrators who contribute relatively more to the Wikipedia project exhibit a lower preference for reciprocity on average is further supplemented by the fact that they also exhibit lower levels of trust, as measured by the proportion of their endowment that they transferred as trustors in the Trust game (see table A.2). To be sure, the transfer decisions in the Trust game are irrelevant to our field test of existing economic theories of prosocial motives for contributing to realworld public goods. Rather, those decisions were elicited as part of our procedure for providing a second measure of taste for reciprocity, when subjects were put in the position of trustees in the Trust game. That said, we find it striking that this group is the only one within which we can find an economically and statistically significant relationship between trust levels and the number of contributions made to Wikipedia, which tends to align with the above finding that highly contributing administrators are less reciprocal on average. We hypothesize that such negative correlations between Wikipedia participation and prosociality levels within the group of administrators might be related to the fact that those engaged contributors self-selected into performing a policing role within the community of editors.

\section{3 The role of social image motives}

As we have seen from the previous section, reciprocity, as opposed to altruism, appears as the major private social preference associated with the trajectory of Wikipedia users from a non-contributor to a regular contributor. This preference, however, does not seem to continue to predict the trajectories of the highest regular contributors to Wikipedia, and is even negatively associated with the number of contributions made by Wikipedia administrators. In this section, we rely on observational data to investigate the role of social image motives in our subjects' willingness to contribute to the Wikipedia project.

Within our sample of regular and admin subjects, respectively, we code as "social signaler" those who have a personal Wikipedia user page whose size (in bytes) is higher than the median in each group. Alternatively, from the sub-sample of subjects who received social awards - or Barnstars - from other Wikipedia contributors (i.e. 456 subjects, representing $54 \%$ of our total sample), we code as "social signalers" those who decided to advertize at least one of those awards on their personal user page. ${ }^{25}$ According to this measure, $54 \%$ of Barnstars receivers reveal a preference for social image. Importantly, $81 \%$ of Barnstars receivers in the sample of regular subjects have a contribution record that is higher than the median, so that the coefficient on this variable will mainly tells us about the role

${ }^{25}$ As a robustness check, we also computed the proportion of received Barnstars that subjects decided to manually move to their personal user pages as an alternative indicator of their social image motive. The results are unaffected (table available from the authors upon request). 
of social image motives in the above median group. As we expect subjects who receive more Barnstars to have a higher probability of exhibiting one of them on their personal user page (at least in a statistical sense), and as the total number of Barnstars received should be highly correlated with the number of Wikipedia contributions made, we include the total number of Barnstars received as a control in all the regressions that rely on this measure of social image to avoid potential spurious correlations.

Table 5.1 presents the results of those new estimations for all regular contributors. We see from column (1) that subjects who reveal a preference for social image by having a relatively larger Wikipedia user page make on average $269 \%$ more contributions to Wikipedia. This highly statistically significant result confirms the hypothesis that those who care relatively more about their social image within the community of editors also contribute more to the Wikipedia project.

To check for heterogeneous effects, we also run the exact same regression as in model (1) separately in the above and the below median groups. We can see from column (4) that, in agreement with what we found in the case of reciprocity, the coefficient on social image increases by $38 \%$ in the below median group and remains highly statistically significant. Contrary to what we found in the case of reciprocity, however, a revealed preference for social image continues to reliably predict the number of contributions made to Wikipedia within the group of highest contributors to Wikipedia, even if the magnitude of the coefficient is significantly reduced. Indeed, in the above median group, social signalers make on average $30 \%$ more contributions to the Wikipedia project. This last result is confirmed when we rely on our Barnstars data to construct an alternative indicator of social image and obtain that social signalers make on average 33\% more contributions to Wikipedia (see column (10)).

So far, we have established that our measures of reciprocity and social image - but not altruism can predict the trajectory of Wikipedia users from a non-contributor to a regular contributor. Unlike reciprocity, however, a taste for social image continues to predict the number of field contributions made by our subjects even within the group of highest contributors to Wikipedia.

Building upon this result, a natural question to ask is that of the nature of the interaction (if any) between reciprocity and social image as other-regarding motives for contributing to Wikipedia. We answer this question by investigating whether our experimental measures of reciprocity predict the number of contributions that our subjects make to Wikipedia differentially, depending on whether they reveal a concern for their social image within the Wikipedia community or not. To achieve this goal, we estimate models (1), (4), (7) and (10) again. This time, however, we estimate the coefficients on the reciprocity motive separately for social signalers and non social signalers.

Focusing on column (2) and (3), we can see that, irrespective of the experimental measure of reciprocity that we consider, the predictive power of this preference on the number of field contributions to Wikipedia seems to be concentrated within the group of non social signalers, that is contributors who do not reveal a relatively high preference for social image within Wikipedia. Restricting the sample to the below median group and running the same regressions reinforces this conclusion. We can see from columns (5) and (6) that the coefficients on reciprocity in the group of social signalers are positive, but remain statistically insignificant. The coefficients on reciprocity in the group of non social signalers, by contrast, remain highly statistically significant and increase by $66 \%$ and $10 \%$, respectively. Finally, turning our attention to the above median group, we obtain a picture that is consistent with that of table 4 where we found no relationship anymore between reciprocity and the number of contributions made to Wikipedia by the most highly engaged contributors. Indeed, none of the reciprocity coefficients reaches the $5 \%$ significance level in the above median group. This is true irrespective of whether we consider the sub-group of social signalers or non social signalers, and of 
whether we compute our measure of social image using our personal user page size data (columns (8) and (9)) or using our Barnstars data (columns (11) and (12)).

At the end of the day, what those estimations suggest is that both reciprocity and social image are powerful predictors of individuals' willingness to sustain cooperation in a real-world public goods like environment such as Wikipedia, but that they seem to be substitutable rather than complementary motivational drivers (i.e. both motives are at play, but in different subsets of the population of contributors).

\section{[TABLE 5.1 ABOUT HERE]}

We end this section by presenting our estimations for the group of Wikipedia administrators in table 5.2. A general fact is that when compared to the group of engaged Wikipedia contributors from which they recruit their members (i.e. excluding new contributors), Wikipedia administrators seem to be significantly more concerned about their social image within Wikipedia, as their personal user pages are on average $39 \%$ larger than those of the engaged contributors $(p=0.001)$ and the proportion of their received Barnstars that they decide to advertize on their personal user pages is $10 \%$ higher $(p=0.041)$.

Still, we can see from column (1) that our social image measure continues to predict the number of field contributions made to Wikipedia, even within the group of Wikipedia administrators. Specifically, Wikipedia administrators who reveal a relatively higher taste for social image as measured by the size of their user page make on average $42 \%$ more contributions to the Wikipedia project. This relationship, however, does not hold anymore if we compute our social image variable using our Barnstars data (see column (4)).

Turning our attention to the study of the interaction between reciprocity and social image (see columns (2), (3), (5) and (6)), we observe that the coefficients on the reciprocity variables are negative in all estimations, irrespective of whether we consider the sub-group of administrators who reveal a relatively lower or relatively higher taste for social image. This result tends to reinforce the conclusion from table 4, in which we uncovered a negative relationship between administrators' taste for reciprocity and their contributions to Wikipedia. It is interesting to note, however, that only one of the reciprocity coefficients out of four is statistically significant in the sub-group of relatively low social signalers, while all of them are highly statistically significant in the sub-group of high social signalers. This indicates that the average negative relationship between administrators' taste for reciprocity and Wikipedia participation is in fact largely driven by the population of high social signalers.

\section{[TABLE 5.2 ABOUT HERE]}

\section{Conclusions}

In this paper, we provide the first comprehensive field test of existing economic theories of prosocial motives for contributing to real-world public goods. We elicited the social preferences of a diverse sample of 850 Wikipedia contributors with an online experiment coupled with observational data and tested for their predictive power over records of contributions to the Wikipedia project. In this peer production economy in which extrinsic incentives play no role in shaping individual behavior, we find a 
sizeable relationship between prosocial motivations and individuals' willingness to sustain cooperation. Specifically, it is possible to summarize our results as follows:

1. For regular (i.e. non admin) contributors:

i. Reciprocity and social image - but not altruism - appear as underlying social preferences that predict the trajectory of Wikipedia users from a non-contributor to an engaged contributor.

ii. In this process, reciprocity and social image seem to be substitutes rather than complementary motivational drivers (i.e. each motive is at play, but in different subsets of the population of contributors).

iii. A taste for reciprocity does not continue to predict the trajectory of those Wikipedia users who become super-contributor, while a taste for social image does.

2. For Wikipedia administrators:

i. On average, engaged contributors who hold admin status reveal a higher taste for social image than regular engaged contributors.

ii. Even within this group of high social signalers, there is some evidence that administrators who value their social image relatively more contribute more.

iii. There is strong evidence that within the group of administrators, Wikipedia participation is negatively associated with a taste for reciprocity (and, incidentally, to trust levels as measured by the Trust game), with the effect being mostly concentrated among those who reveal a relatively higher taste for social image.

The results of our field experiment have important theoretical implications, as they strongly support the models of voluntary provision of public goods based on reciprocity and social image motives, but not those based on altruistic motives. In this respect, it is reinsuring to note that this overarching conclusion is strongly consistent with the results of the extensive literature from the lab that has tried to test for the role of those three classes of social motives in people's willingness to sustain cooperation in repeated public goods experiments (see footnote 6).

On top of being able to test for a link between individual measures of preferences and independently collected records of contributions to a real-world public good, our theoretically comprehensive approach also allows us to study the nature of the interaction between the preferences that appear to matter. We find that while both a taste for reciprocity and social image predict the trajectory of Wikipedia users from a non-contributor to an engaged one, those motivational drivers tend to be substitutable rather than complementary in our population of subjects. Further, only social image continues to correlate with the contribution records of the population of super contributors to the public good.

Taken globally, our results strikingly corroborate the findings of the single related study of Wikipedia in the economics literature: focusing on the Chinese Wikipedia, Zhang and Zhu (2011) find that after an exogenous reduction in contributors' group size, the nonblocked contributors decreased their contributions by $42.8 \%$ on average. The authors hypothesize that their findings might be due to what they call "social effects", that is social benefits that would accrue to contributors as the size of their group grows. Our results support and precise their hypothesis, as models based on reciprocity and social image would both predict an increase in individual contributions following an increase in the size of the group of contributors, while models based on altruism would either predict no impact (in the case of warm-glow) or even a decrease (in the case of pure altruism) in individual contributions. 
Focusing on the small body of engaged Wikipedia contributors who hold admin status, we find that when compared to the group of engaged but regular Wikipedia contributors from which it recruits its members, this group reveals a higher average taste for social image. However, even within this group of high social signalers, we find that revealing a relatively higher taste for social image continues to predict higher records of contributions to the project. Perhaps the most surprising of our findings is that we also find a strong negative relationship between Wikipedia participation and taste for reciprocity (and, incidentally, trust, as measured by the Trust game) within the group of Wikipedia administrators, so that relatively higher contributors in this position are actually less prosocial on average. We hypothesize that this finding could be due to those engaged contributors having self-selected into holding the "stick" of the Wikipedia community to perform a policing role within the extended body of Wikipedia editors.

Beyond their theoretical relevance, our results also have important implications for practitioners who seek to leverage intrinsic motivations to promote Internet-based voluntary cooperation for the provision of public goods. If anything, from Wikipedia to Open Source Software, the impressive achievements of Internet-based peer production in the last 15 years are an indication that intrinsic motivations generally construed (including, but not limited to, prosocial motivations) can be very powerful at incentivizing work, and should represent more than a simple add-on to the economic theory of optimal extrinsic incentives schemes. Wikipedia is a textbook case for the peer production model, as well as a striking success story. How much this model of voluntary provision of public goods over the Internet will continue to scale-up probably depends on how good practitioners will be at efficiently designing large scale human interaction systems that incentivize voluntary participation. Our findings suggest that to maximize individual contributions, some special emphasis should be put on the human interactivity side of those systems coupled with some public recognition mechanisms, which will notably continue to incentivize the highest potential contributors.

We are, of course, only beginning to uncover the nature of the intrinsic motives that drive individuals to voluntarily sustain cooperation in the field. These motives are likely to be diverse. Much more field work needs to be done to see if the literature will be able to identify some general underlying preferences that would be systematically associated with sustained patterns of contribution to realworld public goods, irrespective of the context in which such contributions take place. It could also be, however, that the motives that drive contributions highly depend on the nature of the public good considered, which could in turn explain some of the contradicting laboratory results in the literature (see Vesterlund (2012) and Ostrom (1990)). Although the Internet is a rather specific field of study, we suggest that there is increasing scope for learning from an online approach coupling the tools of experimental economics with computational social science techniques. This is true in the sense that the Internet allows to run experiments eliciting individual preference parameters from large and diverse populations, and to connect those preferences to very detailed observational data on individual behavior. As such, we view our methodology as a way to relieve the traditional tension between internal and external validity in experimental economics.

\section{References}

Anderson, S.P., Goeree, J.K. \& Holt, C.A., 1998. A theoretical analysis of altruism and decision error in public goods games. Journal of Public Economics, 70(2), pp.297-323. 
Andreoni, J., 1995. Cooperation in Public-Goods Experiments: Kindness or Confusion? The American Economic Review, 85(4), pp.891-904.

Andreoni, J., 1989. Giving with Impure Altruism: Applications to Charity and Ricardian Equivalence. Journal of Political Economy, 97(6), pp.1447-1458.

Andreoni, J., 1990. Impure Altruism and Donations to Public Goods: A Theory of Warm-Glow Giving. The Economic Journal, 100(401), pp.464-477.

Andreoni, J. \& Bernheim, B.D., 2009. Social Image and the 50-50 Norm: A Theoretical and Experimental Analysis of Audience Effects. Econometrica, 77(5), pp.1607-1636.

Andreoni, J. \& Miller, J., 2002. Giving According to GARP: An Experimental Test of the Consistency of Preferences for Altruism. Econometrica, 70(2), pp.737-753.

Andreoni, J. \& Petrie, R., 2004. Public goods experiments without confidentiality: a glimpse into fundraising. Journal of Public Economics, 88(7-8), pp.1605-1623.

Andreoni, J., Rao, J.M. \& Trachtman, H., 2011. Avoiding The Ask: A Field Experiment on Altruism, Empathy, and Charitable Giving. Working Paper.

Ariely, D., Bracha, A. \& Meier, S., 2009. Doing Good or Doing Well? Image Motivation and Monetary Incentives in Behaving Prosocially. American Economic Review, 99(1), pp.544-55.

Baldwin, C. \& Von Hippel, E., 2011. Modeling a Paradigm Shift: From Producer Innovation to User and Open Collaborative Innovation. Organization Science, 22(6), pp.1399-1417.

Barr, A. \& Serneels, P., 2009. Reciprocity in the workplace. Experimental Economics, 12(1), pp.99-112.

Bénabou, R. \& Tirole, J., 2006. Incentives and Prosocial Behavior. The American Economic Review, 96(5), pp.1652-1678.

Benkler, Y., 2002. Coase's Penguin, or, Linux and "The Nature of the Firm." The Yale Law Journal, 112(3), pp.369-446.

Benkler, Y., 2006. The Wealth of Networks: How Social Production Transforms Markets and Freedom, New Haven, CT, USA: Yale University Press.

Benz, M. \& Meier, S., 2008. Do people behave in experiments as in the field?-evidence from donations. Experimental Economics, 11(3), pp.268-281.

Burlando, R. \& Guala, F., 2005. Heterogeneous Agents in Public Goods Experiments. Experimental Economics, 8(1), pp.35-54.

Carpenter, J. \& Myers, C.K., 2010. Why volunteer? Evidence on the role of altruism, image, and incentives. Journal of Public Economics, 94(11-12), pp.911-920.

Carpenter, J. \& Seki, E., 2011. Do social preferences increase productivity? Field experimental evidence from fishermen in Toyama Bay. Economic Inquiry, 49(2), pp.612-630.

Charness, G. \& Yang, C.-L., 2007. Endogenous Group Formation and Public Goods Provision: Exclusion, Exit, Mergers, and Redemption. Working Paper. 
Cinyabuguma, M., Page, T. \& Putterman, L., 2005. Cooperation under the threat of expulsion in a public goods experiment. Journal of Public Economics, 89(8), pp.1421-1435.

DellaVigna, S., List, J.A. \& Malmendier, U., 2012. Testing for Altruism and Social Pressure in Charitable Giving. The Quarterly Journal of Economics, 127(1), pp.1-56.

Dohmen, T. et al., 2011. Individual Risk Attitudes: Measurement, Determinants and Behavioral Consequences. Journal of the European Economic Association, 9(3), pp.522-550.

Dufwenberg, M. \& Kirchsteiger, G., 2004. A theory of sequential reciprocity. Games and Economic Behavior, 47(2), pp.268-298.

Ellingsen, T. \& Johannesson, M., 2011. Conspicuous generosity. Journal of Public Economics, 95(9-10), pp.1131-1143.

Ellingsen, T. \& Johannesson, M., 2008. Pride and Prejudice: The Human Side of Incentive Theory. The American Economic Review, 98(3), pp.990-1008.

Falk, A. \& Fischbacher, U., 2006. A theory of reciprocity. Games and Economic Behavior, 54(2), pp.293315.

Fehr, E. \& Camerer, C.F., 2004. Measuring Social Norms and Preferences Using Experimental Games: A Guide for Social Scientists. Foundations of Human Sociality, 1(9), pp.55-96.

Fehr, E. \& Leibbrandt, A., 2011. A field study on cooperativeness and impatience in the Tragedy of the Commons. Journal of Public Economics, 95(9-10), pp.1144-1155.

Fischbacher, U. \& Gächter, S., 2010. Social Preferences, Beliefs, and the Dynamics of Free Riding in Public Goods Experiments. The American Economic Review, 100(1), pp.541-556.

Fischbacher, U., Gächter, S. \& Fehr, E., 2001. Are people conditionally cooperative? Evidence from a public goods experiment. Economics Letters, 71(3), pp.397-404.

Gächter, S. \& Thöni, C., 2005. Social learning and voluntary cooperation among like-minded people. Journal of the European Economic Association, 3(2-3), pp.303-314.

Goeree, J.K., Holt, C.A. \& Laury, S.K., 2002. Private costs and public benefits: unraveling the effects of altruism and noisy behavior. Journal of Public Economics, 83(2), pp.255-276.

Greenstein, S. \& Zhu, F., 2012. Collective Intelligence and Neutral Point of View: The Case of Wikipedia. National Bureau of Economic Research Working Paper.

Gunnthorsdottir, A., Houser, D. \& McCabe, K., 2007. Disposition, history and contributions in public goods experiments. Journal of Economic Behavior \& Organization, 62(2), pp.304-315.

Hergueux, J. \& Jacquemet, N., 2013. Social Preferences in the Online Laboratory: A Randomized Experiment. Working Paper.

Holländer, H., 1990. A Social Exchange Approach to Voluntary Cooperation. The American Economic Review, 80(5), pp.1157-1167.

Karlan, D.S., 2005. Using Experimental Economics to Measure Social Capital and Predict Financial Decisions. The American Economic Review, 95(5), pp.1688-1699. 
Kittur, A. et al., 2007. Power of the few vs. wisdom of the crowd: Wikipedia and the rise of the bourgeoisie. Proceeding of the CIGCHI Conference on Human Factors in Computing Systems.

Laury, S.K. \& Taylor, L.O., 2008. Altruism spillovers: Are behaviors in context-free experiments predictive of altruism toward a naturally occurring public good? Journal of Economic Behavior $\mathcal{E}$ Organization, 65(1), pp.9-29.

Lazer, D. et al., 2009. Life in the network: the coming age of computational social science. Science (New York, N.Y.), 323(5915), pp.721-723.

Leibbrandt, A., 2012. Are social preferences related to market performance? Experimental Economics, 15(4), pp.589-603.

Lerner, J. \& Tirole, J., 2002. Some Simple Economics of Open Source. The Journal of Industrial Economics, 50(2), pp.197-234.

Oliveira, A.D., Croson, R.T.A. \& Eckel, C.C., 2009a. Are Preferences Stable Across Domains? An Experimental Investigation of Social Preferences in the Field. Working Paper.

Oliveira, A.D., Croson, R.T.A. \& Eckel, C.C., 2009b. One Bad Apple: Uncertainty and Heterogeneity in Public Good Provision. Working Paper.

Ostrom, E., 1990. Governing the Commons: The Evolution of Institutions for Collective Action, Cambridge University Press.

Page, T., Putterman, L. \& Unel, B., 2005. Voluntary Association in Public Goods Experiments: Reciprocity, Mimicry and Efficiency. The Economic Journal, 115(506), pp.1032-1053.

Palfrey, T.R. \& Prisbrey, J.E., 1997. Anomalous Behavior in Public Goods Experiments: How Much and Why? The American Economic Review, 87(5), pp.829-846.

Rabin, M., 1993. Incorporating Fairness into Game Theory and Economics. The American Economic Review, 83(5), pp.1281-1302.

Reagle, Joseph M., 2010. Good Faith Collaboration: The Culture of Wikipedia, MIT Press.

Rege, M. \& Telle, K., 2004. The impact of social approval and framing on cooperation in public good situations. Journal of Public Economics, 88(7-8), pp.1625-1644.

Vesterlund, Lise, 2012. Voluntary Giving to Public Goods: Moving Beyond the Linear VCM. Working Paper.

Vesterlund, Lise, Wilhelm, Mark \& Xie, Huan, 2009. Motives for charitable giving. Working Paper.

Zhang, X. \& Zhu, F., 2011. Group Size and Incentives to Contribute: A Natural Experiment at Chinese Wikipedia. The American Economic Review, 101(4), pp.1601-1615. 


\section{Tables and figures}

Figure 1. The instruction screen of the Public Goods game

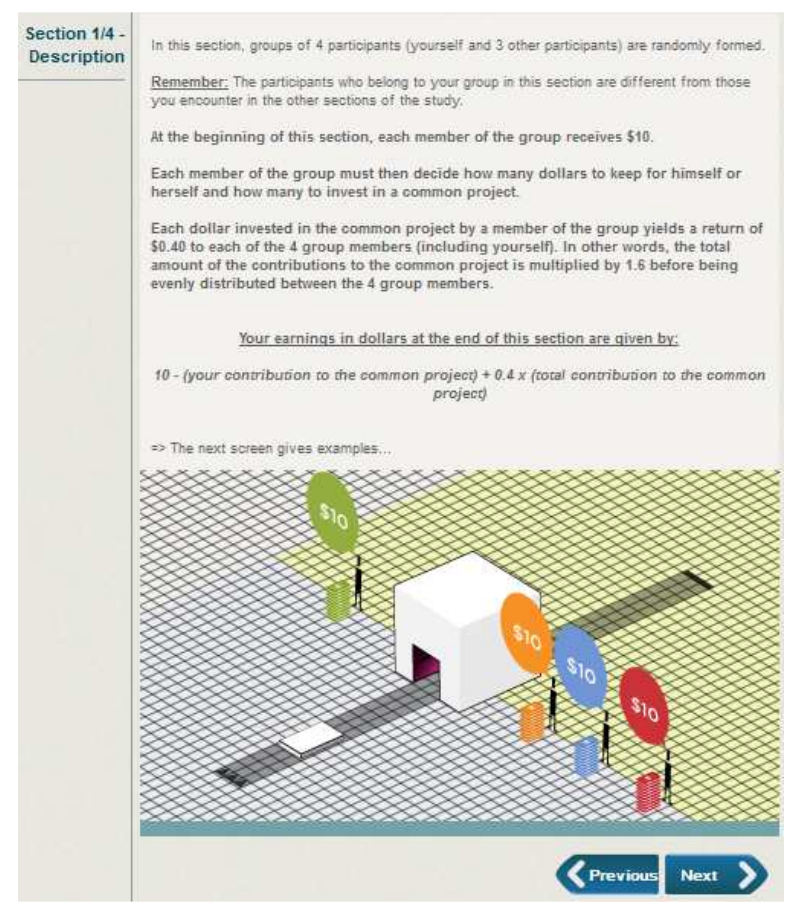

Figure 2. The decision screen of the conditional Public Goods game

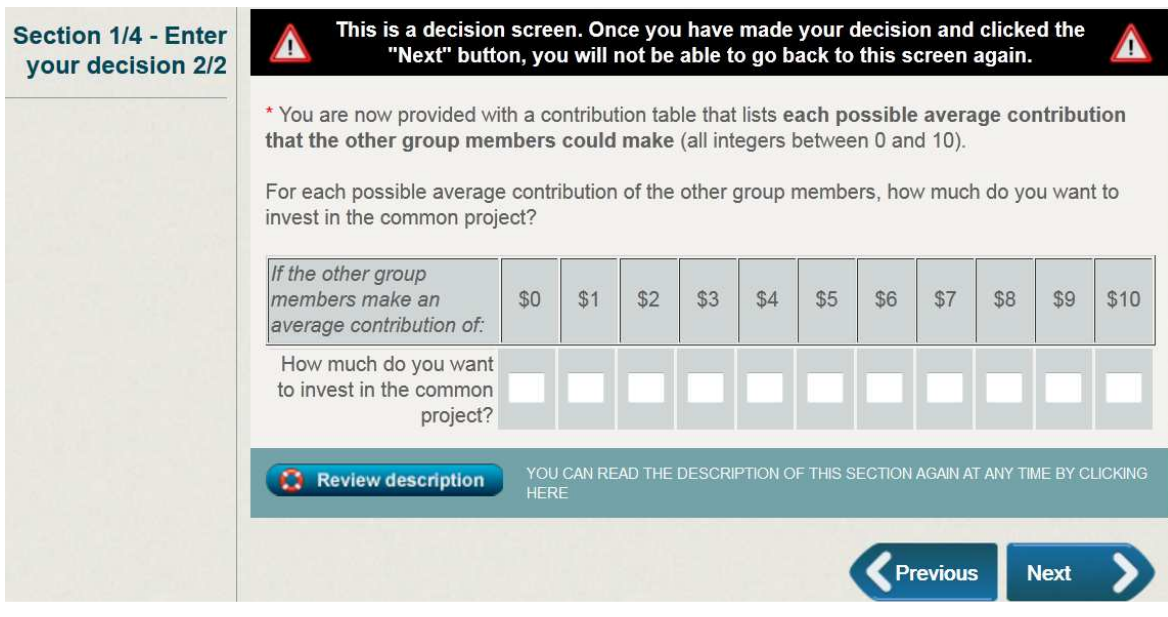

Figure 3. A typical Barnstar

The Teamwork Barnstar
Cas, for being one of those awesome
wikipedians who produces great content in a
collegial manner, helping out all over, and
great dispute resolution. - Rlevse $\bullet$ Talk
13:50,26 December 2009 (UTC)


Figure 4. The Wikipedia recruitment banner

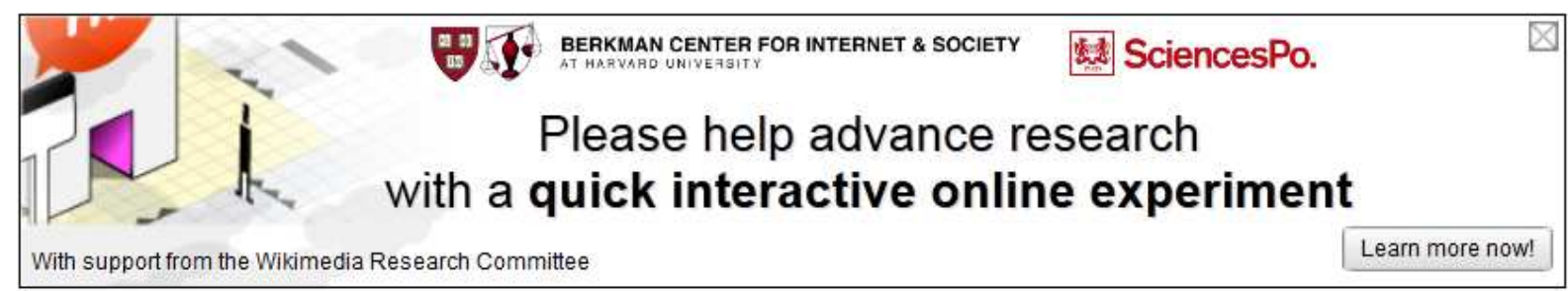

Figure 5. Distribution of the number of Wikipedia contributions per experimental group: whole population vs. study participants
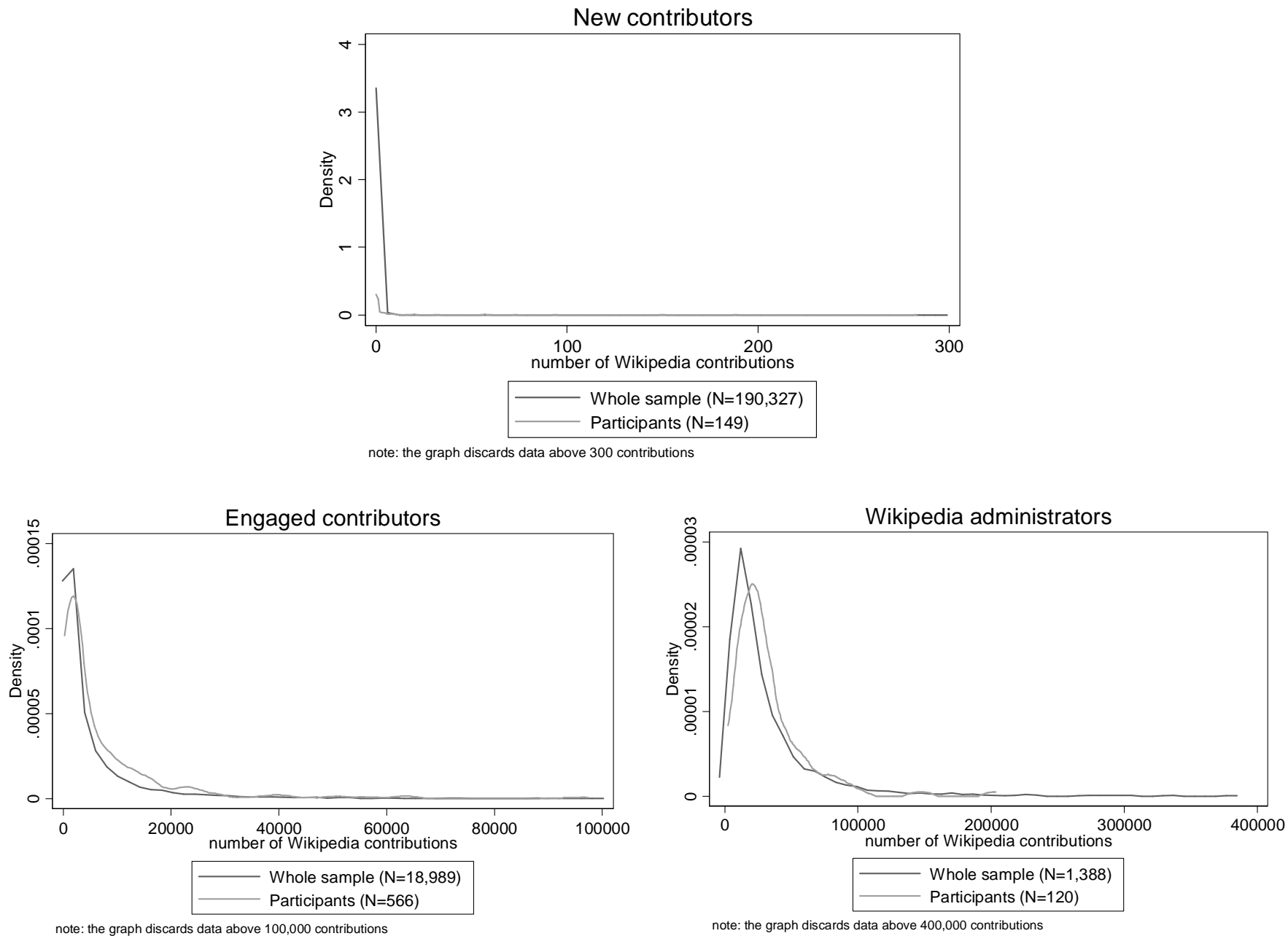

Notes: Kernel density estimates. 
Table 1. Descriptive statistics

\begin{tabular}{|c|c|c|c|c|}
\hline & $\begin{array}{c}\text { New } \\
\text { contributors } \\
\end{array}$ & $\begin{array}{c}\text { Engaged } \\
\text { contributors }\end{array}$ & Administrators & Other \\
\hline Number of observations $(N)$ & 149 & 566 & 120 & 15 \\
\hline \multicolumn{5}{|l|}{ DEPENDENT VARIABLE } \\
\hline \multirow[t]{3}{*}{ Mean - number of Wikipedia contributions } & 8.64 & 9719.83 & 41229.24 & 543.13 \\
\hline & $(3.56)$ & $(23519.39)$ & $(86191.33)$ & $(1664.19)$ \\
\hline & {$[0 ; 273]$} & [303; 364157] & {$[2475 ; 922895]$} & [0;6547] \\
\hline \multicolumn{5}{|l|}{ SOCIAL PREFERENCES MEASURES } \\
\hline \multicolumn{5}{|l|}{ Cooperation $(N=850)$} \\
\hline \multirow[t]{2}{*}{ Proportion of endowment unconditionally contributed - Public Goods } & 5.58 & 6.64 & 6.19 & 7.13 \\
\hline & $(0.36)$ & $(0.33)$ & $(0.33)$ & $(0.29)$ \\
\hline \multicolumn{5}{|l|}{ Altruism $(N=405)$} \\
\hline \multirow[t]{2}{*}{ (i) Proportion of endowment transferred - Dictator } & 0.38 & 0.36 & 0.42 & 0.28 \\
\hline & $(0.30)$ & $(0.30)$ & $(0.28)$ & $(0.26)$ \\
\hline \multirow[t]{2}{*}{ (ii) Proportion of endowment transferred - in-group Dictator } & 0.46 & 0.45 & 0.48 & 0.40 \\
\hline & $(0.29)$ & $(0.30)$ & $(0.28)$ & $(0.20)$ \\
\hline \multicolumn{5}{|l|}{ Reciprocity $(N=850 \& N=445)$} \\
\hline \multirow[t]{2}{*}{ (i) Average proportion of endowment conditionally contributed - Public Goods } & 0.45 & 0.54 & 0.52 & 0.52 \\
\hline & $(0.27)$ & $(0.24)$ & $(0.24)$ & $(0.26)$ \\
\hline \multirow[t]{2}{*}{ (ii) Average proportion of amount returned - Trust } & 0.45 & 0.51 & 0.46 & 0.54 \\
\hline & $(0.25)$ & $(0.23)$ & $(0.23)$ & $(0.22)$ \\
\hline \multicolumn{5}{|l|}{ Social image $(N=456 \mathcal{E} N=850)$} \\
\hline \multirow[t]{2}{*}{ (i) Mean size of Wikipedia user page (in bytes) } & 453.81 & 5586.24 & 9179.64 & 1238.60 \\
\hline & $(3597.62)$ & $(10859.97)$ & $(11012.09)$ & $(3438.12)$ \\
\hline Number of Barnstars receivers & 4 & 340 & 109 & 3 \\
\hline \multirow[t]{2}{*}{ Mean - number of Barnstars received } & 1.5 & 6.14 & 16.8 & 5 \\
\hline & $(0.58)$ & $(8.57)$ & $(15.99)$ & $(6.93)$ \\
\hline \multirow[t]{2}{*}{ (ii) Proportion signaling Barnstars } & 0.25 & 0.50 & 0.70 & 0.33 \\
\hline & $(0.50)$ & $(0.50)$ & $(0.46)$ & $(0.58)$ \\
\hline \multicolumn{5}{|l|}{ DEMOGRAPHIC VARIABLES } \\
\hline \multirow[t]{2}{*}{ Age } & 27 & 34 & 34 & 33 \\
\hline & $(11.81)$ & $(14.73)$ & $(12.86)$ & $(8.84)$ \\
\hline \multirow[t]{2}{*}{ Proportion female } & 0.15 & 0.09 & 0.11 & 0.07 \\
\hline & $(0.36)$ & $(0.29)$ & $(0.31)$ & $(0.26)$ \\
\hline \multirow[t]{2}{*}{ Degree level } & 3.97 & 4.55 & 4.88 & 4.73 \\
\hline & $(1.92)$ & $(1.80)$ & $(1.64)$ & $(1.75)$ \\
\hline \multirow[t]{2}{*}{ Salary level } & 3.17 & 3.80 & 4.01 & 3.79 \\
\hline & $(2.15)$ & $(2.34)$ & $(2.25)$ & $(2.12)$ \\
\hline \multirow[t]{2}{*}{ Risk aversion level } & 6.16 & 5.66 & 5.53 & 4.67 \\
\hline & $(2.36)$ & $(2.34)$ & $(2.38)$ & $(2.09)$ \\
\hline
\end{tabular}

Notes: Standard errors are reported in parenthesis. mean number of Wikipedia contributions $=$ mean number of modifications implemented in Wikipedia (minimum and maximum values are reported in brackets). Degree level: $1=$ "less than high school"; $2=$ "high school"; $3=$ "some college"; 4 = "2 years college degree"; $5=$ " 4 years college degree (BA, BS)"; 6 = "masters degree"; 7 = "professional degree (MD, JD)"; $8=$ "doctoral degree". Salary level (monthly): 1 = "0 USD"; 2 = "less than 1000 USD"; 3 = "between 1000 and 2000 USD"; 4 = "between 2000 and 3000 USD"; 5 = "between 3000 and 4000 USD"; 6 = "between 4000 and 5000 USD"; 7 = "between 5000 and 7500 USD"; $8=$ "between 7500 and 10000 USD"; 9 = "more than 10000 USD". Risk aversion level = whether subjects generally see themselves as fully prepared to take risks as opposed to generally trying to avoid taking risks: $0=$ "unwilling to take risks" to $10=$ "fully prepared to take risks". 
Table 2. Sample common demographic characteristics:

Wikimedia editor survey vs. our study

\begin{tabular}{lcc}
\hline \hline \multicolumn{2}{l}{$\begin{array}{c}\text { 2011 Wikimedia } \\
\text { editor survey }\end{array}$} & Our study \\
\hline Age & & \\
12 to 17 & $13 \%$ & $4 \%$ \\
18 to 21 & $14 \%$ & $17 \%$ \\
22 to 29 & $26 \%$ & $30 \%$ \\
30 to 39 & $19 \%$ & $20 \%$ \\
40 or more & $28 \%$ & $28 \%$ \\
Gender & & \\
$\quad$ Proportion female & $9 \%$ & $10 \%$ \\
Education level & & \\
$\quad$ Primary & $9 \%$ & $5 \%$ \\
Secondary & $30 \%$ & $31 \%$ \\
Bachelors / associate & $35 \%$ & $34 \%$ \\
Master's & $18 \%$ & $22 \%$ \\
PhD & $8 \%$ & $7 \%$ \\
\hline
\end{tabular}

Notes: The Wikimedia editor survey excludes respondents under 12 and over 82 from the sample. The age and gender statistics are based on the population of respondents with a positive number of Wikipedia contributions $(\mathrm{N}=4,930)$. The Education level statistics are based on the whole population of respondents $(\mathrm{N}=5,073)$. In this table, we base our own statistics on the same calculation rules.

Table 3. Association between number of Wikipedia contributions and taste for cooperation

\begin{tabular}{|c|c|c|c|c|c|}
\hline & $(1)$ & (2) & (3) & (4) & (5) \\
\hline $\begin{array}{l}\text { Dependent variable: } \\
\text { number of Wikipedia contributions }\end{array}$ & $\begin{array}{l}\text { Whole } \\
\text { sample }\end{array}$ & $\begin{array}{l}\text { Whole } \\
\text { sample }\end{array}$ & $\begin{array}{l}\text { Below } \\
\text { median }\end{array}$ & $\begin{array}{l}\text { Above } \\
\text { median }\end{array}$ & Admins \\
\hline Cooperation - Public Goods & & $\begin{array}{c}0.400^{* * *} \\
(0.126)\end{array}$ & $\begin{array}{c}0.578^{* * *} \\
(0.195)\end{array}$ & $\begin{array}{l}0.0253 \\
(0.137)\end{array}$ & $\begin{array}{l}-0.430^{*} \\
(0.220)\end{array}$ \\
\hline age & $\begin{array}{l}0.0167^{* * *} \\
(0.00306)\end{array}$ & $\begin{array}{l}0.0163^{* * *} \\
(0.00310)\end{array}$ & $\begin{array}{l}0.0139^{* * *} \\
(0.00524)\end{array}$ & $\begin{array}{c}0.00505 \\
(0.00344)\end{array}$ & $\begin{array}{l}0.0167^{* * *} \\
(0.00542)\end{array}$ \\
\hline female & $\begin{array}{c}-0.365^{* *} \\
(0.147)\end{array}$ & $\begin{array}{c}-0.346^{* *} \\
(0.147)\end{array}$ & $\begin{array}{c}-0.652^{* * *} \\
(0.244)\end{array}$ & $\begin{array}{l}-0.0323 \\
(0.152)\end{array}$ & $\begin{array}{l}-0.160 \\
(0.252)\end{array}$ \\
\hline degree level & $\begin{array}{l}0.0582^{* *} \\
(0.0246)\end{array}$ & $\begin{array}{l}0.0494^{* *} \\
(0.0250)\end{array}$ & $\begin{array}{l}0.0852^{* *} \\
(0.0370)\end{array}$ & $\begin{array}{c}0.0166 \\
(0.0309)\end{array}$ & $\begin{array}{l}-0.0369 \\
(0.0445)\end{array}$ \\
\hline salary level & $\begin{array}{l}0.00282 \\
(0.0200)\end{array}$ & $\begin{array}{l}0.00262 \\
(0.0199)\end{array}$ & $\begin{array}{c}-0.00758 \\
(0.0312)\end{array}$ & $\begin{array}{l}-0.0134 \\
(0.0225)\end{array}$ & $\begin{array}{l}-0.0465 \\
(0.0303)\end{array}$ \\
\hline prepared to take risks & $\begin{array}{l}-0.0325^{*} \\
(0.0169)\end{array}$ & $\begin{array}{c}-0.0426^{* *} \\
(0.0174)\end{array}$ & $\begin{array}{c}-0.0809^{* * *} \\
(0.0272)\end{array}$ & $\begin{array}{l}-0.00250 \\
(0.0198)\end{array}$ & $\begin{array}{c}0.0127 \\
(0.0280)\end{array}$ \\
\hline Constant & $\begin{array}{c}8.310^{* * *} \\
(0.175)\end{array}$ & $\begin{array}{c}8.149^{* * *} \\
(0.183)\end{array}$ & $\begin{array}{c}5.651^{* * *} \\
(0.282)\end{array}$ & $\begin{array}{c}9.411^{* * *} \\
(0.195)\end{array}$ & $\begin{array}{c}10.62^{* * *} \\
(0.300)\end{array}$ \\
\hline $\mathrm{N}$ & 649 & 649 & 325 & 324 & 113 \\
\hline Pseudo R ${ }^{2}$ & 0.00507 & 0.00596 & 0.00923 & 0.000493 & 0.00526 \\
\hline
\end{tabular}

Notes: Negative binomial estimates. Standard errors are reported in parenthesis. ${ }^{*},{ }^{* *}$ and ${ }^{* * *}$ denote statistical significance at the 10, 5 and $1 \%$ levels. Cooperation - Public Goods = proportion of endowment unconditionally contributed to the public good. Model (1) is all non admin subjects; model (2) is non admin subjects below the median number of Wikipedia contributions (i.e. 1905 contributions); model (3) is non admin subjects above the median number of Wikipedia contributions; model (4) is all admin subjects. 
Table 4. Association between number of Wikipedia contributions and taste for altruism (panel A) and reciprocity (panel B)

\begin{tabular}{|c|c|c|c|c|c|c|c|c|}
\hline & (1) & (2) & (3) & (4) & (5) & (6) & (7) & (8) \\
\hline $\begin{array}{l}\text { Dependent variable: } \\
\text { number of Wikipedia contributions }\end{array}$ & $\begin{array}{l}\text { Whole } \\
\text { sample }\end{array}$ & $\begin{array}{l}\text { Whole } \\
\text { sample }\end{array}$ & $\begin{array}{r}\text { Below } \\
\text { median }\end{array}$ & $\begin{array}{l}\text { Below } \\
\text { median }\end{array}$ & $\begin{array}{r}\text { Above } \\
\text { median }\end{array}$ & $\begin{array}{l}\text { Above } \\
\text { median }\end{array}$ & Admins & Admins \\
\hline \multicolumn{9}{|l|}{ Panel A: Altruism } \\
\hline Altruism - Dictator & $\begin{array}{l}-0.183 \\
(0.207)\end{array}$ & & $\begin{array}{l}-0.184 \\
(0.332)\end{array}$ & & $\begin{array}{l}-0.239 \\
(0.224)\end{array}$ & & $\begin{array}{c}0.181 \\
(0.317)\end{array}$ & \\
\hline Altruism - Dictator in-group & & $\begin{array}{l}-0.184 \\
(0.207)\end{array}$ & & $\begin{array}{l}-0.177 \\
(0.332)\end{array}$ & & $\begin{array}{l}-0.319 \\
(0.222)\end{array}$ & & $\begin{array}{c}0.199 \\
(0.353)\end{array}$ \\
\hline Constant & $\begin{array}{c}8.237^{* * *} \\
(0.257)\end{array}$ & $\begin{array}{c}8.281^{* * *} \\
(0.265)\end{array}$ & $\begin{array}{c}5.854^{* * * *} \\
(0.404)\end{array}$ & $\begin{array}{c}5.894^{* * *} \\
(0.413)\end{array}$ & $\begin{array}{c}9.175^{* * *} \\
(0.269)\end{array}$ & $\begin{array}{c}9.257^{* * *} \\
(0.275)\end{array}$ & $\begin{array}{c}10.10^{* * *} \\
(0.301)\end{array}$ & $\begin{array}{c}10.09^{* * * *} \\
(0.307)\end{array}$ \\
\hline Control variables & Yes & Yes & Yes & Yes & Yes & Yes & Yes & Yes \\
\hline $\mathrm{N}$ & 305 & 305 & 159 & 159 & 146 & 146 & 56 & 56 \\
\hline Pseudo R $^{2}$ & 0.00698 & 0.00699 & 0.00834 & 0.00833 & 0.00226 & 0.00257 & 0.0112 & 0.0112 \\
\hline \multicolumn{9}{|l|}{ Panel B: Reciprocity } \\
\hline Reciprocity - Public Goods & $\begin{array}{l}0.378^{* *} \\
(0.162)\end{array}$ & & $\begin{array}{r}0.796^{* * *} \\
(0.246)\end{array}$ & & $\begin{array}{l}-0.107 \\
(0.187)\end{array}$ & & $\begin{array}{c}-0.631^{* *} \\
(0.307)\end{array}$ & \\
\hline Reciprocity - Trust & & $\begin{array}{l}0.443^{*} \\
(0.242)\end{array}$ & & $\begin{array}{c}1.136^{* * *} \\
(0.392)\end{array}$ & & $\begin{array}{l}0.0424 \\
(0.273)\end{array}$ & & $\begin{array}{c}-0.990^{* *} \\
(0.447)\end{array}$ \\
\hline Constant & $\begin{array}{c}8.189^{* * *} \\
(0.183)\end{array}$ & $\begin{array}{c}8.183^{* * *} \\
(0.260)\end{array}$ & $\begin{array}{c}5.660^{* * * *} \\
(0.278)\end{array}$ & $\begin{array}{c}5.430^{* * *} \\
(0.395)\end{array}$ & $\begin{array}{c}9.457^{* * *} \\
(0.200)\end{array}$ & $\begin{array}{c}9.548^{* * *} \\
(0.275)\end{array}$ & $\begin{array}{c}10.61^{* * *} \\
(0.299)\end{array}$ & $\begin{array}{c}10.97^{* * * *} \\
(0.525)\end{array}$ \\
\hline Control variables & Yes & Yes & Yes & Yes & Yes & Yes & Yes & Yes \\
\hline $\mathrm{N}$ & 649 & 344 & 325 & 166 & 324 & 178 & 113 & 57 \\
\hline Pseudo $\mathrm{R}^{2}$ & 0.00554 & 0.00516 & 0.00959 & 0.0142 & 0.000535 & 0.000572 & 0.00538 & 0.00594 \\
\hline
\end{tabular}

Notes: Negative binomial estimates. Standard errors are reported in parenthesis. ${ }^{*}, * *$ and ${ }^{* * *}$ denote statistical significance at the 10,5 and $1 \%$ levels. Altruism - Dictator $=$ proportion of endowment transferred in the Dictator game. Altruism - Dictator in-group = proportion of endowment transferred in the directed Dictator game. Reciprocity - Public Goods = average proportion of endowment conditionally contributed in the Public Goods game strategy method; Reciprocity - Trust = average proportion of amount received that is returned by the subject in the Trust game strategy method. Models (1) and (2) are all non admin subjects; models (3) and (4) are non admin subjects below the median number of Wikipedia contributions (i.e. 1905 contributions); models (5) and (6) are non admin subjects above the median number of Wikipedia contributions; models (7) and (8) are all admin subjects. 
Table 5.1 Association between number of Wikipedia contributions and social image motivation (non admin subjects)

\begin{tabular}{|c|c|c|c|c|c|c|c|c|c|c|c|c|}
\hline & $(1)$ & $(2)$ & (3) & $(4)$ & $(5)$ & (6) & $(7)$ & $(8)$ & (9) & $(10)$ & $(11)$ & $(12)$ \\
\hline $\begin{array}{l}\text { Dependent variable: } \\
\text { number of Wikipedia contributions }\end{array}$ & $\begin{array}{l}\text { Whole } \\
\text { sample }\end{array}$ & $\begin{array}{l}\text { Whole } \\
\text { sample }\end{array}$ & $\begin{array}{l}\text { Whole } \\
\text { sample }\end{array}$ & $\begin{array}{l}\text { Below } \\
\text { median }\end{array}$ & $\begin{array}{l}\text { Below } \\
\text { median }\end{array}$ & $\begin{array}{l}\text { Below } \\
\text { median }\end{array}$ & $\begin{array}{l}\text { Above } \\
\text { median }\end{array}$ & $\begin{array}{l}\text { Above } \\
\text { median }\end{array}$ & $\begin{array}{l}\text { Above } \\
\text { median }\end{array}$ & $\begin{array}{l}\text { Whole } \\
\text { sample }\end{array}$ & $\begin{array}{l}\text { Whole } \\
\text { sample }\end{array}$ & $\begin{array}{l}\text { Whole } \\
\text { sample }\end{array}$ \\
\hline Social signaler (user page) & $\begin{array}{l}1.305^{* * *} \\
(0.0845)\end{array}$ & $\begin{array}{c}1.648^{* * *} \\
(0.190)\end{array}$ & $\begin{array}{c}2.021^{* * *} \\
(0.281)\end{array}$ & $\begin{array}{c}1.805^{* * *} \\
(0.126)\end{array}$ & $\begin{array}{c}2.096^{* * *} \\
(0.270)\end{array}$ & $\begin{array}{l}2.133^{* * *} \\
(0.466)\end{array}$ & $\begin{array}{c}0.261^{* * *} \\
(0.101)\end{array}$ & $\begin{array}{c}0.678^{* * *} \\
(0.230)\end{array}$ & $\begin{array}{c}0.562 \\
(0.348)\end{array}$ & & & \\
\hline Social signaler (Barnstars) & & & & & & & & & & $\begin{array}{l}0.288^{* * *} \\
(0.0969)\end{array}$ & $\begin{array}{l}0.665^{* * *} \\
(0.224)\end{array}$ & $\begin{array}{l}0.812^{* *} \\
(0.335)\end{array}$ \\
\hline Reciprocity - Public Goods x Social signaler (user page) & & $\begin{array}{l}-0.0987 \\
(0.198)\end{array}$ & & & $\begin{array}{l}0.354 \\
(0.304)\end{array}$ & & & $\begin{array}{l}-0.442^{*} \\
(0.228)\end{array}$ & & & & \\
\hline Reciprocity - Public Goods x non Social signaler (user page) & & $\begin{array}{l}0.563^{* *} \\
(0.250)\end{array}$ & & & $\begin{array}{c}0.932^{* * *} \\
(0.318)\end{array}$ & & & $\begin{array}{c}0.338 \\
(0.321)\end{array}$ & & & & \\
\hline Reciprocity - Trust x Social signaler (user page) & & & $\begin{array}{l}-0.294 \\
(0.309)\end{array}$ & & & $\begin{array}{l}0.632 \\
(0.586)\end{array}$ & & & $\begin{array}{l}-0.0176 \\
(0.316)\end{array}$ & & & \\
\hline Reciprocity - Trust x non Social signaler (user page) & & & $\begin{array}{c}1.067^{* * *} \\
(0.376)\end{array}$ & & & $\begin{array}{l}1.173^{* *} \\
(0.501)\end{array}$ & & & $\begin{array}{c}0.451 \\
(0.507)\end{array}$ & & & \\
\hline Reciprocity - Public Goods x Social signaler (Barnstars) & & & & & & & & & & & $\begin{array}{l}-0.324 \\
(0.242)\end{array}$ & \\
\hline Reciprocity - Public Goods x non Social signaler (Barnstars) & & & & & & & & & & & $\begin{array}{c}0.349 \\
(0.263)\end{array}$ & \\
\hline Reciprocity - Trust x Social signaler (Barnstars) & & & & & & & & & & & & $\begin{array}{l}-0.614^{*} \\
(0.337)\end{array}$ \\
\hline Reciprocity - Trust x non Social signaler (Barnstars) & & & & & & & & & & & & $\begin{array}{c}0.154 \\
(0.497)\end{array}$ \\
\hline nb Barnstars & & & & & & & & & & $\begin{array}{l}0.0405^{* * *} \\
(0.00287)\end{array}$ & $\begin{array}{l}0.0400^{* * *} \\
(0.00288)\end{array}$ & $\begin{array}{l}0.0371^{* * *} \\
(0.00380)\end{array}$ \\
\hline Constant & $\begin{array}{c}7.759^{* * *} \\
(0.168)\end{array}$ & $\begin{array}{c}7.514^{* * *} \\
(0.203)\end{array}$ & $\begin{array}{c}7.218^{* * *} \\
(0.300)\end{array}$ & $\begin{array}{c}5.292^{* * *} \\
(0.233)\end{array}$ & $\begin{array}{c}4.923^{* * *} \\
(0.273)\end{array}$ & $\begin{array}{c}4.543^{* * *} \\
(0.401)\end{array}$ & $\begin{array}{c}9.300^{* * *} \\
(0.195)\end{array}$ & $\begin{array}{c}9.134^{* * *} \\
(0.239)\end{array}$ & $\begin{array}{c}9.234^{* * *} \\
(0.349)\end{array}$ & $\begin{array}{c}8.471^{* * *} \\
(0.192)\end{array}$ & $\begin{array}{c}8.265^{* * *} \\
(0.248)\end{array}$ & $\begin{array}{c}8.520^{* * *} \\
(0.349)\end{array}$ \\
\hline Control variables & Yes & Yes & Yes & Yes & Yes & Yes & Yes & Yes & Yes & Yes & Yes & Yes \\
\hline $\mathrm{N}$ & 649 & 649 & 344 & 325 & 325 & 166 & 324 & 324 & 178 & 308 & 308 & 164 \\
\hline Pseudo R ${ }^{2}$ & 0.0256 & 0.0261 & 0.0270 & 0.0467 & 0.0491 & 0.0562 & 0.00150 & 0.00221 & 0.00214 & 0.0192 & 0.0197 & 0.0223 \\
\hline
\end{tabular}


Table 5.2 Association between number of Wikipedia contributions and social image motivation (admin subjects)

\begin{tabular}{|c|c|c|c|c|c|c|}
\hline & (1) & (2) & (3) & (4) & (5) & (6) \\
\hline $\begin{array}{l}\text { Dependent variable: } \\
\text { number of Wikipedia contributions }\end{array}$ & Admins & Admins & Admins & Admins & Admins & Admins \\
\hline Social signaler (user page) & $\begin{array}{c}0.354^{* * *} \\
(0.135)\end{array}$ & $\begin{array}{l}0.601^{*} \\
(0.324)\end{array}$ & $\begin{array}{c}0.364 \\
(0.485)\end{array}$ & & & \\
\hline Social signaler (Barnstars) & & & & $\begin{array}{l}-0.0202 \\
(0.160)\end{array}$ & $\begin{array}{l}-0.245 \\
(0.296)\end{array}$ & $\begin{array}{l}0.0149 \\
(0.464)\end{array}$ \\
\hline Reciprocity - Public Goods x Social signaler (user page) & & $\begin{array}{l}-0.854^{* *} \\
(0.389)\end{array}$ & & & & \\
\hline Reciprocity - Public Goods x non Social signaler (user page) & & $\begin{array}{l}-0.370 \\
(0.441)\end{array}$ & & & & \\
\hline Reciprocity - Trust $x$ Social signaler (user page ) & & & $\begin{array}{c}-1.070^{* *} \\
(0.546)\end{array}$ & & & \\
\hline Reciprocity - Trust $x$ non Social signaler (user page) & & & $\begin{array}{l}-0.686 \\
(0.788)\end{array}$ & & & \\
\hline Reciprocity - Public Goods x Social signaler (Barnstars) & & & & & $\begin{array}{c}-1.041^{* * *} \\
(0.328)\end{array}$ & \\
\hline Reciprocity - Public Goods x non Social signaler (Barnstars) & & & & & $\begin{array}{c}-1.293^{* * *} \\
(0.461)\end{array}$ & \\
\hline Reciprocity - Trust $x$ Social signaler (Barnstars) & & & & & & $\begin{array}{c}-0.981^{* *} \\
(0.458)\end{array}$ \\
\hline Reciprocity - Trust $x$ non Social signaler (Barnstars) & & & & & & $\begin{array}{l}-0.159 \\
(0.978)\end{array}$ \\
\hline nb Barnstars & & & & $\begin{array}{l}0.0167^{* * *} \\
(0.00371)\end{array}$ & $\begin{array}{l}0.0195^{* * *} \\
(0.00342)\end{array}$ & $\begin{array}{l}0.0339^{* * *} \\
(0.00716)\end{array}$ \\
\hline Constant & $\begin{array}{c}10.24^{* * *} \\
(0.321)\end{array}$ & $\begin{array}{c}10.55^{* * *} \\
(0.329)\end{array}$ & $\begin{array}{c}10.05^{* * *} \\
(0.596)\end{array}$ & $\begin{array}{c}10.31^{* * *} \\
(0.299)\end{array}$ & $\begin{array}{c}10.35^{* * *} \\
(0.340)\end{array}$ & $\begin{array}{c}10.77^{* * *} \\
(0.654)\end{array}$ \\
\hline Control variables & Yes & Yes & Yes & Yes & Yes & Yes \\
\hline $\mathrm{N}$ & 102 & 102 & 49 & 113 & 113 & 57 \\
\hline Pseudo R ${ }^{2}$ & 0.0112 & 0.0172 & 0.0201 & 0.00640 & 0.00832 & 0.00670 \\
\hline
\end{tabular}

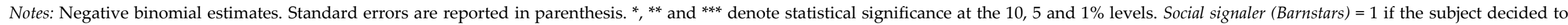

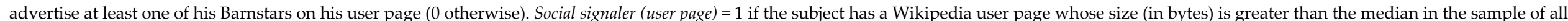

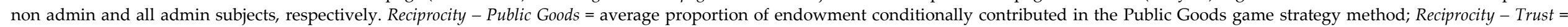

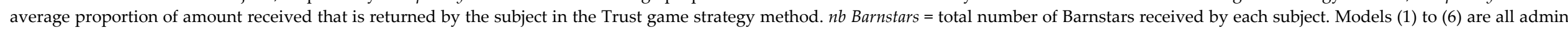
subjects. 


\section{Appendix}

Table A.1. Association between number of Wikipedia contributions and taste for reciprocity, controlling for altruism

\begin{tabular}{lcccccc:ccc}
\hline \hline & $(1)$ & $(2)$ & $(3)$ & $(4)$ & $(5)$ & $(6)$ & $(7)$ & $(8)$ \\
\hline $\begin{array}{l}\text { Dependent variable: } \\
\text { number of Wikipedia contributions }\end{array}$ & $\begin{array}{c}\text { Whole } \\
\text { sample }\end{array}$ & $\begin{array}{c}\text { Whole } \\
\text { sample }\end{array}$ & $\begin{array}{c}\text { Below } \\
\text { median }\end{array}$ & $\begin{array}{c}\text { Below } \\
\text { median }\end{array}$ & $\begin{array}{c}\text { Above } \\
\text { median }\end{array}$ & $\begin{array}{c}\text { Above } \\
\text { median }\end{array}$ & Admins & Admins \\
\hline Reciprocity - Public Goods & & & & & & & & & \\
& 0.181 & 0.193 & $0.681^{*}$ & $0.700^{*}$ & -0.00265 & 0.0889 & $-1.382^{* * *}$ & $-1.418^{* * *}$ \\
& $(0.261)$ & $(0.264)$ & $(0.394)$ & $(0.396)$ & $(0.300)$ & $(0.309)$ & $(0.424)$ & $(0.430)$ \\
Altruism - Dictator & -0.237 & & -0.390 & & -0.238 & & 0.237 & \\
& $(0.221)$ & & $(0.350)$ & & $(0.253)$ & & $(0.305)$ & \\
Altruism - Dictator in-group & & -0.245 & & -0.406 & & -0.358 & & 0.321 \\
& & $(0.223)$ & & $(0.349)$ & & $(0.260)$ & & $(0.343)$ \\
Constant & $8.197^{* * *}$ & $8.254^{* * *}$ & $5.735^{* * *}$ & $5.822^{* * *}$ & $9.176^{* * *}$ & $9.236^{* * *}$ & $10.34^{* * *}$ & $10.32^{* * *}$ \\
& $(0.264)$ & $(0.268)$ & $(0.410)$ & $(0.416)$ & $(0.290)$ & $(0.285)$ & $(0.294)$ & $(0.297)$ \\
Control variables & & & & & & & & \\
N & Yes & Yes & Yes & Yes & Yes & Yes & Yes & Yes \\
Pseudo R & 305 & 305 & 159 & 159 & 146 & 146 & 56 & 56 \\
\hline
\end{tabular}

Notes: Negative binomial estimates. Standard errors are reported in parenthesis. ${ }^{*},{ }^{* *}$ and ${ }^{* * *}$ denote statistical significance at the 10, 5 and 1\% levels. Reciprocity - Public Goods = average proportion of endowment conditionally contributed in the Public Goods game strategy method; Altruism - Dictator = proportion of endowment transferred in the Dictator game. Altruism Dictator in-group = proportion of endowment transferred in the directed Dictator game. Models (1) and (2) are all non admin subjects; models (3) and (4) are non admin subjects below the median number of Wikipedia contributions (i.e. 1905 contributions); models (5) and (6) are non admin subjects above the median number of Wikipedia contributions; models (7) and (8) are all admin subjects.

Table A.2. Association between number of Wikipedia contributions and trust

\begin{tabular}{|c|c|c|c|c|}
\hline & $(1)$ & (2) & (3) & (4) \\
\hline $\begin{array}{l}\text { Dependent variable: } \\
\text { number of Wikipedia contributions }\end{array}$ & $\begin{array}{l}\text { Whole } \\
\text { sample }\end{array}$ & $\begin{array}{l}\text { Below } \\
\text { median }\end{array}$ & $\begin{array}{l}\text { Above } \\
\text { median }\end{array}$ & Admins \\
\hline Send - Trust & $\begin{array}{l}0.0780 \\
(0.180)\end{array}$ & $\begin{array}{l}-0.0265 \\
(0.272)\end{array}$ & $\begin{array}{l}-0.0393 \\
(0.187)\end{array}$ & $\begin{array}{l}-0.730^{* *} \\
(0.309)\end{array}$ \\
\hline Constant & $\begin{array}{c}8.185^{* * *} \\
(0.274)\end{array}$ & $\begin{array}{c}5.859^{* * *} \\
(0.426)\end{array}$ & $\begin{array}{c}9.198^{* * *} \\
(0.287)\end{array}$ & $\begin{array}{c}10.52^{* * *} \\
(0.319)\end{array}$ \\
\hline Control variables & Yes & Yes & Yes & Yes \\
\hline $\mathrm{N}$ & 305 & 159 & 146 & 56 \\
\hline Pseudo $\mathrm{R}^{2}$ & 0.00687 & 0.00819 & 0.00191 & 0.0150 \\
\hline
\end{tabular}

Notes: Negative binomial estimates. Standard errors are reported in parenthesis. ${ }^{*}{ }^{* *}$ and ${ }^{* * *}$ denote statistical significance at the 10, 5 and $1 \%$ levels. Send - Trust $=$ proportion of endowment sent in the Trust game. Model (1) is all non admin subjects; model (2) is non admin subjects below the median number of Wikipedia contributions (i.e. 1905 contributions); model (3) is non admin subjects above the median number of Wikipedia contributions; model (4) is all admin subjects. 